Type of the Paper (Article, Review, Communication, etc.)

\title{
Effect of the aerosol vertical distribution on the modelling of solar radiation
}

\author{
Ilias Fountoulakis 1,*, Kyriakoula Papachristopoulou 1,2,3, Emmanouil Proestakis 1, Vassilis Amiridis ${ }^{1}$, Charalam- \\ pos Kontoes ${ }^{1}$ and Stelios Kazadzis ${ }^{3}$
}

1 Institute for Astronomy, Astrophysics, Space Applications and Remote Sensing, National Observatory of Athens (IAASARS/NOA), GR-15236 Athens, Greece 1; (IF: i.fountoulakis@noa.gr; KP: kpapachr@noa.gr; EP: proestakis@noa.gr; CK: kontoes@noa.gr; VA: vamoir@noa.gr)

2 Laboratory of Climatology and Atmospheric Environment, Sector of Geography and Climatology, Department of Geology and Environment, National and Kapodistrian University of Athens (LACAE/NKUA), Athens, Greece

3 Physicalisch-Meteorologisches Observatorium Davos, World Radiation Center, CH-7260 Davos, Switzerland; (SK: Stelios.Kazadzis@pmodwrc.ch)

* Correspondence: i.fountoulakis@noa.gr

\begin{abstract}
Default aerosol extinction coefficient profiles are commonly used instead of measured profiles in radiative transfer modelling, increasing the uncertainties in the simulations. The present study aims to determine the magnitude of these uncertainties and contribute towards the understanding of the complex interactions between aerosols and solar radiation. Default, artificial and measured profiles of the aerosol extinction coefficient are used to simulate the profiles of different radiometric quantities in the atmosphere for different surface, atmospheric, and aerosol properties and for four spectral bands: ultraviolet-B, ultraviolet-A, visible, and near infrared. Case studies are performed over different areas in Europe and North Africa. Analysis of the results shows that under cloudless-skies, changing the altitude of an artificial aerosol layer has minor impact on the levels of shortwave radiation at the top and the bottom of the atmosphere, even for high aerosol loads. Differences up to $30 \%$ were however detected for individual spectral bands. Using measured instead of default profiles for the simulations leads to more significant differences in the atmosphere, which become very large during dust episodes $(10-60 \%$ for actinic flux at altitudes between 1 and $2 \mathrm{~km}$, and up to $15 \mathrm{~K} /$ day for heating rates depending on site and solar elevation).
\end{abstract}

Keywords: aerosol profile; aerosol extinction coefficient; aerosol radiative effects; spectral solar radiation; solar radiation profile

\section{Introduction}

Solar radiation is the primary source of energy on earth, affecting many physical, chemical and biological processes on the planet. Alterations in the amount or the spectral distribution of solar radiation that reaches the Earth's surface impact Earth's climate and may have significant direct and indirect implications on life on Earth [1-3]. In addition to changes in surface solar radiation (SSR), changes in its vertical distribution are also very significant since they affect the energy balance, and subsequently physical and dynamical processes (formation of clouds, wind patterns, etc.) which strongly influence Earth's climate [4]. The distribution of solar radiation in the atmosphere and at the Earth's surface is affected primary by clouds, and under cloud-free conditions by atmospheric aerosols, trace gases and water vapor. Aerosols scatter and absorb solar radiation, affecting directly its distribution in the atmosphere and its levels at the surface. Furthermore, they affect the distribution of solar radiation indirectly through their effects on the formation and the properties of clouds (indirect and semidirect effects) [4]. The shapes, sizes, and chemical composition of aerosols vary significantly, resulting to correspondingly high variability in their optical properties, and subsequently their interactions with solar radiation [5-9]. 
Due to their high complexity, the interactions between aerosols and solar radiation are not yet completely understood and aerosols constitute one of the main uncertainty sources in the projections of global and regional climate models [10-12], as well as in the satellite algorithms used for the estimation of SSR (e.g., [13-16]). The spectral distribution of the optical properties of aerosols in conjunction with differences in the scattering and the absorption of radiation at different wavelengths by atmospheric molecules further increases the uncertainty in the modelling of solar radiation [17-19]. In a recent study, Mishra et al. [20] showed that there is strong spectral dependence of the aerosol radiative effects on the aerosol layer height (aerosol radiative effects increase with the aerosol layer height in the ultraviolet and decrease in the visible and the near infrared).

Due to inadequate information for the vertical distribution of aerosols it is common to use simplified extinction coefficient profiles (assuming that aerosols are mostly concentrated near the surface and/or that they decrease exponentially with increasing altitude) $[21,22]$ for the modelling of their radiative effects. Although the assumption of exponential decrease is relatively accurate for the estimation of the SSR over certain environments (e.g., for urban aerosols) [23], few information is available for the effect of using a more realistic instead of a theoretical profile to perform radiative transfer (RT) simulations when the real profiles of aerosols decline significantly from the ideal theoretical profile. For example, volcanic, dust, or biomass burning aerosols are frequently transported to long distances away from their sources, travelling at high altitudes in the atmosphere [2429], resulting to aerosol profiles which differ significantly from the theoretical. While volcanic aerosols contribute a very small amount in the overall global aerosol mixture, biomass-burning and dust aerosols have a very strong contribution over wide regions of the planet [30]. Over the Mediterranean Basin and North Africa, dust plays a key role in the attenuation of solar irradiance, and near the extra-tropics its role is comparable, or more significant (over arid or semi-arid areas), with respect to the role of clouds [31-34]. According to Mishra et al. [20] radiative effects of dust aerosols are the most sensitive to altitude among four different (dust, polluted dust, polluted, scattering) aerosol species. Differences in the sensitivity of the different aerosol types were explained by their relative efficiency to absorption and scattering of solar radiation at different spectral regions. Revel et al. [35] point out that uncertainties in the geographical and vertical distribution of microplastics in the atmosphere contribute significantly in the estimation of their radiative effects. Microplastics can travel to very long distances from their sources and have been detected at very high altitudes, of the order of $3 \mathrm{~km}$, in the atmosphere [36,37]. Fasano et al. [38] showed that even over a pristine Alpine region, transported Saharan dust can increase atmospheric heating rates $(\mathrm{HR})$ by more than $1 \mathrm{~K} /$ day (relative to aerosol-free atmosphere), and at the same time have a negative radiative effect at the top and at the bottom of the atmosphere. At such regions (i.e., Alpine Valleys) changes in atmospheric heating have an immediate impact on the climate of the slopes and are considered among the possible drivers for Elevation-Dependent Warming (EDW) [39,40]. Many studies show that aerosols affect the Asian monsoon water cycle. Aerosol effects on monsoon water cycle dynamics are complex, and depend strongly on the characteristics and the distribution of aerosols [41-43].

Photochemical processes also depend on the amount of available solar radiation, either at particular wavelengths or at broader spectral bands [44-46]. Such processes take place at different altitudes in the atmosphere, determine atmospheric composition, and play a key role for air quality [47-50]. Photolysis rates at a specific altitude in the atmosphere depend on atmospheric composition and solar zenith angle (SZA), but also on the amount and the optical properties of aerosols [51,52] and clouds [53]. Given that during warm, clear-sky days the atmosphere is well-mixed in the planetary boundary layer (PBL), ranging from a few hundreds of meters up to a three kilometers (depending on location and time) [30], photochemical reactions that take place at higher altitudes in the atmosphere can also play significant role for the quality of air near the surface.

The present study aims to shed some light in the following issues: 
- How do changes in the vertical distribution of aerosol optical properties affect the solar radiation that reaches the Earth's surface, and how do they affect the backscattered solar radiation?

- What is the magnitude of differences in the atmospheric heating rates due to changes in the vertical profile of the aerosols?

- How is the vertical distribution of actinic flux (AF), (i.e., the radiometric quantity that is of direct interest for photochemical reactions), affected by changes in the vertical profile of aerosols?

- What is the effect to the spectral solar radiation of different aerosol load and absorption properties for aerosols at different altitudes?

This paper consists an effort to address the above questions for different atmospheric conditions, under cloud-free skies, and for different aerosol loads and properties.

The paper is structured as follows. The datasets and methods that are used to answer the above questions are described in Section 2. The results of the analyses are presented and discussed in Section 3. In Section 4 the main conclusions of the study are summarized. This is a sensitivity study aiming to provide information relative to the magnitude of differences when a more realistic aerosol extinction profile is used instead of a theoretical profile, and to explain the mechanisms that are responsible for the differences.

\section{Data and Methodology}

In the present study, the effect of aerosol extinction profile on the profile of the ultraviolet-B (UVB, 280 - $315 \mathrm{~nm}$ integral), ultraviolet-A (UVA, 315 - $400 \mathrm{~nm}$ integral), visible (VIS, $400-700 \mathrm{~nm}$ integral), near infrared (NIR, $700-3000 \mathrm{~nm}$ integral) and total shortwave (SW, $280-3000 \mathrm{~nm}$ integral) solar radiation was investigated for different aerosol and different atmospheric conditions.

- As a first step, the sensitivity of the solar radiation profile to the altitude of a hypothetical aerosol layer was investigated using artificial aerosol extinction coefficient profiles.

- As a second step, radiative transfer (RT) simulations were performed using aerosol extinction coefficient profiles from the LIdar climatology of Vertical Aerosol Structure for space-based lidar simulation studies (LIVAS) [54] and the results were compared with the results of simulations with the default libRadtran profile [22] which assumes exponential decrease of the aerosol extinction coefficient with altitude in the troposphere.

The simulations were performed for typical and extreme aerosol conditions and for different European and North-African regions. In addition to the AF and the HR, the global irradiance (GI), the direct irradiance (DI), the downwelling diffuse irradiance (DDI) and the upwelling diffuse irradiance (UDI) were simulated, which are the necessary quantities in order to answer to the four questions listed in Section 1. Short descriptions of LIVAS and the basic setup for the RT simulations are provided in Sections 2.1 and 2.2 respectively. Description of the methodology used for the investigation of the role of aerosol profile on the vertical distribution of solar irradiance is provided in Sections 2.3 - 2.5.

\subsection{LIVAS}

LIVAS is a three-dimensional (3-D) multi-wavelength global aerosol and cloud optical database, which provides averaged profiles of aerosol optical properties at 355, 532, 1064, 1570 and $2050 \mathrm{~nm}$ and cloud optical properties at the wavelength of $532 \mathrm{~nm}$ [54]. Established based on CALIPSO (Cloud-Aerosol Lidar and Infrared Pathfinder Satellite; [55]) LIVAS data has been used in various studies for aerosol 3D climatology (e.g., [56,57]). To produce Level 2 (L2) Version 4 (V4) profiles of aerosol and cloud optical properties and layer classification information [58](Kim et al., 2018), LIVAS applies a series of qualityassurance procedures (Tackett et al., 2018), prior averaging in order to generate the Level 3 (L3) aerosol profile products, including, among others, vertical profiles of total-aerosol extinction coefficient and AOD at $532 \mathrm{~nm}$. The original LIVAS database is established on a uniform grid of $1 \circ \times 1 \circ$ spatial resolution, with the CALIPSO original vertical resolution, 
while with respect to the temporal resolution the aerosol optical properties are provided (1) at the CALIPSO per-orbit level, (2) on monthly-means, and (3) on long-term averaged profiles (06/2006-12/2020). However, for the scientific objectives of the present study, the LIVAS total-aerosol extinction coefficient profiles and AODs at 532nm are generated at two spatial resolutions different from the original one. More specifically, the first option of spatial resolution includes LIVAS optical properties when CALIPSO overpasses Athens-Greece, Cairo-Egypt, and Lampedusa-Italy locations within a horizontal radius of 100 $\mathrm{km}$. The second generated spatial resolution, provides LIVAS aerosol optical properties at $5 \circ 55^{\circ}$ spatial resolution for two domains selected especially for the needs of the study, one over the Saharan desert/North-West Africa and the second over Central Europe (more information is provided in Sections 2.4 and 2.5).

\subsection{Radiative Transfer simulations}

The model UVSPEC which is included in the library for radiative transfer (libRadtran) package [59] was used to perform RT simulations. A number of input parameters were explicitly defined for each of the simulations: total column of water vapor (TCWV), total column of ozone (TCO), surface albedo, columnar aerosol optical properties (the aerosol optical depth (AOD), the single scattering albedo (SSA), and the Ångström Exponent $(\mathrm{AE})$ ), and the vertical profile of the extinction coefficient at $532 \mathrm{~nm}$. The latter was then scaled to the value of the AOD at each wavelength. In all cases, the profiles of other than AOD aerosol optical properties (e.g., SSA, AE, asymmetry parameter) were assumed to be constant throughout the atmosphere. A typical, constant value of 0.7 (e.g., [19]) was defined for asymmetry parameter, as well as a standard $\mathrm{CO}_{2}$ concentration of $430 \mathrm{ppb}$. The standard atmospheric profile (standard US atmosphere [60]) was used for all simulations. Thus, the default libRadtran profiles of TCO, TCWV, etc. were scaled to the defined columnar values.

Model outputs were produced for 18 layers between 0 and $8 \mathrm{~km}$ which were denser near the bottom of the atmosphere (BOA) and gradually became sparser with increasing altitude, and at $50 \mathrm{~km}$ considering that differences at the $50 \mathrm{~km}$ altitude are representative for the differences at the top of the atmosphere (TOA). Spectral simulations in the range $280-3000 \mathrm{~nm}$ were performed with a step of $1 \mathrm{~nm}$. The extra-terrestrial solar spectrum suggested by Kurucz [61] and the sdisort [62] pseudospherical 16-stream approximation of the UVSPEC model were used for the simulations. Simulations were performed separately for the four spectral regions: UVB, UVA, VIS, IR. For the simulations in the NIR region, absorption was parametrized using the correlated-k KATO2 distribution [63,64]. Although the latter parameterization introduces some additional uncertainty in the simulations compared to a spectral or pseudo-spectral parameterization, the additional uncertainty is negligible for the NIR integral [65].

The produced spectra were integrated in order to calculate and analyse the total irradiance in the four spectral bands (UVB, UVA, VIS, IR) and the total SW irradiance. The required quantities were finally produced at the model output: DI, GI, DDI, UDI, AF, and HR.

\subsection{Sensitivity study using artificial extinction profiles}

The first step of the study was to perform simulations for five different artificial homogeneous layers of aerosols, with layer base at $0,1,2,3$, and $4 \mathrm{~km}$ (hereafter referred as L0, ..., L4 respectively) from the surface (assuming that the surface is at mean sea level). Three of the five layers are shown in Figure 1. The width of each layer was $1.5 \mathrm{~km}$. Aerosol extinction coefficient above and below each layer was considered zero. Simulations were performed for combinations of different atmospheric and surface parameters, as well as different aerosol optical properties (see Table 1). For each spectral band, the AOD was considered to be independent from wavelength for the simulations (i.e., $\mathrm{AE}$ was set to zero). 


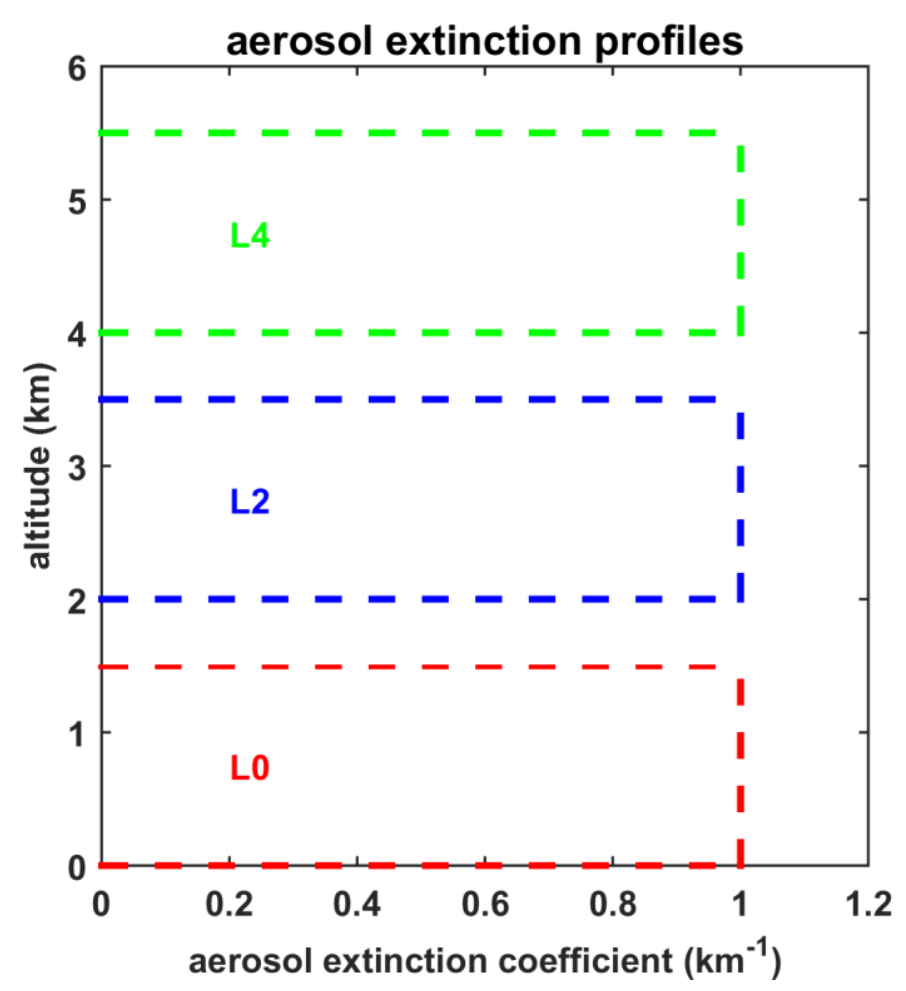

Figure 1. Three of the five artificial aerosol profiles that were used for the simulations (here for AOD $=1.5)$.

Table 1. UVSPEC model input parameters

\begin{tabular}{ll}
\hline property & values \\
\hline SZA & $20^{\circ}, 40^{\circ}, 60^{\circ}, 80^{\circ}$ \\
AOD (all wavelengths) & $0.2,0.5,1.0$ \\
SSA (all wavelengths) & $0.75,0.95$ \\
Asymmetry factor & 0.7 \\
AE & 0 \\
TCO & $350 \mathrm{DU}$ \\
TCWV & $10,30 \mathrm{~mm}$ \\
Surface albedo & $0.1,0.4,0.8$ \\
\hline
\end{tabular}

For the same sets of parameters and different extinction coefficient profiles, comparisons between the vertical profiles of the different radiometric quantities were performed. In all cases, the results for elevated aerosol layers were compared with the results for L0. This way it was possible to investigate the effect of different aerosol layer altitudes and understand the physical mechanisms which are responsible for the differences in the profiles of the radiometric quantities.

\subsection{Simulations using theoretical and LIVAS profiles for typical aerosol conditions}

Aerosol extinction profiles at $532 \mathrm{~nm}$ from the LIVAS climatology were averaged for two $5^{\circ} \times 5^{\circ}$ regions with centres at North-West Saharan desert, Africa $\left(32.5^{\circ} \mathrm{N}, 7.5^{\circ} \mathrm{E}\right)$, and Central-East Europe $\left(47.5^{\circ} \mathrm{N}, 17.5^{\circ} \mathrm{E}\right.$ ) (see Figure 2), for the period 06/2006 - 12/ 2020. In the following, the two regions are referred as NW Africa and CE Europe respectively. Accordingly, from the daily LIVAS profiles, monthly averaged profiles were calculated and were subsequently averaged again to calculate seasonal profiles for winter (December, January, February; DJF), spring (March, April, May; MAM), summer (June, July, August; JJA), and autumn (September, October, November; SON). Seasonal profiles were used to perform RT simulations. RT simulations were also performed using the libRadtran 
default profile [22]. RT simulations for each season were performed for both profiles assuming climatological seasonal averages for TCWV, TCO, aerosol optical properties (AOD, SSA, AE), and surface albedo.

Climatological seasonal TCWV from Copernicus Atmospheric Monitoring Service (CAMS) [66], TCO from Ozone Monitoring Instrument (OMI) [67], and AOD retrievals at $550 \mathrm{~nm}$ from the MODerate resolution Imaging Spectroradiometer (MODIS) onboard Aqua satellite (Collection 6.1; [68]) were averaged for the same areas and seasons and used for the simulations. The utilized quality assured MODIS-Aqua $550 \mathrm{~nm}$ AOD product was obtained by MIDAS dataset [56]. Seasonal climatological averages for the period $2006-$ 2020 were calculated from monthly averaged surface albedo from The Modern-Era Retrospective Analysis for Research and Applications, Version 2 (MERRA-2) climatology [69], and was used for the simulations in VIS and IR. Surface albedo in UV differs significantly from surface albedo in VIS for particular land-surface types such as deserts. Thus, typical values were used [70,71], since large scale climatological data are not available. Seasonally averaged SSA and AE were calculated from monthly averages which were derived from the Max Planck Aerosol Climatology version 2 (MACv2) [72] and were used for the RT simulations. The above parameters are listed in Tables 2-4.

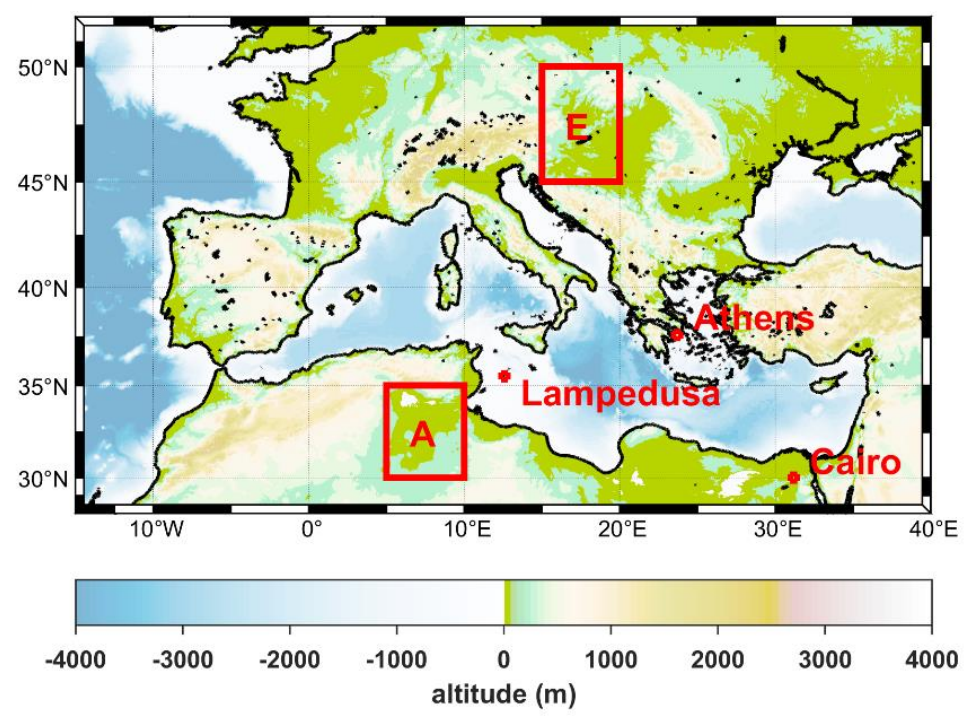

Figure 2. Map with the areas and the sites for which analyses were performed. A and E represent the two areas at North-West Africa and Central-East Europe respectively for which the LIVAS profiles were averaged. 
Table 2: TCO, TCWV, surface albedo and AOD at $550 \mathrm{~nm}$ used in the simulations for NW Africa and CE Europe.

\begin{tabular}{|c|c|c|c|c|}
\hline & winter & spring & summer & autumn \\
\hline \multicolumn{5}{|c|}{$550 \mathrm{~nm}$ AOD } \\
\hline NW Africa & 0.19 & 0.35 & 0.35 & 0.26 \\
\hline CE Europe & 0.07 & 0.18 & 0.22 & 0.13 \\
\hline \multicolumn{5}{|c|}{ TCWV (mm) } \\
\hline NW Africa & 11.4 & 14.6 & 22.3 & 20.4 \\
\hline CE Europe & 9.6 & 14.4 & 25.7 & 17.4 \\
\hline \multicolumn{5}{|c|}{ Total ozone (DU) } \\
\hline NW Africa & 299.4 & 318.3 & 298.4 & 282.2 \\
\hline CE Europe & 333.3 & 358.6 & 320.2 & 287.8 \\
\hline \multicolumn{5}{|c|}{ Surface albedo } \\
\hline NW Africa VIS/IR & 0.42 & 0.40 & 0.41 & 0.41 \\
\hline NW Africa UVB/UVA & 0.10 & 0.10 & 0.10 & 0.10 \\
\hline CE Europe VIS/IR & 0.15 & 0.15 & 0.15 & 0.15 \\
\hline CE Europe UVB/UVA & 0.05 & 0.05 & 0.05 & 0.05 \\
\hline
\end{tabular}

Table 3: SSA used in the simulations for NW Africa and CE Europe. For each spectral band, independent from wavelength SSA was assumed.

\begin{tabular}{lccccc}
\hline & & winter & spring & summer & autumn \\
\hline NW Africa & UVB & 0.84 & 0.77 & 0.81 & 0.80 \\
& UVA & 0.85 & 0.78 & 0.82 & 0.81 \\
& VIS & 0.93 & 0.93 & 0.94 & 0.93 \\
& IR & 0.94 & 0.96 & 0.96 & 0.96 \\
CE Europe & UVB & 0.80 & 0.86 & 0.87 & 0.83 \\
& UVA & 0.81 & 0.87 & 0.88 & 0.85 \\
& VIS & 0.87 & 0.91 & 0.92 & 0.90 \\
& IR & 0.86 & 0.91 & 0.91 & 0.89 \\
\hline
\end{tabular}

Table 4: AE used in the simulations for NW Africa and CE Europe

\begin{tabular}{lccccc}
\hline & & winter & spring & summer & autumn \\
\hline NW Africa & UVB & 1.32 & 0.74 & 1.04 & 0.89 \\
& UVA & 1.32 & 0.74 & 1.04 & 0.89 \\
& VIS & 1.32 & 0.74 & 1.04 & 0.89 \\
& IR & 0.65 & 0.20 & 0.31 & 0.30 \\
CE Europe & UVB & 1.32 & 1.52 & 1.66 & 1.41 \\
& UVA & 1.32 & 1.52 & 1.66 & 1.41 \\
& VIS & 1.32 & 1.52 & 1.66 & 1.41 \\
& IR & 1.32 & 1.30 & 1.40 & 1.27 \\
\hline
\end{tabular}

\subsection{Simulations using theoretical and LIVAS profiles for high aerosol load}

Mediterranean countries are often affected by strong dust events resulting to high AODs and extinction coefficient profiles that differ significantly from the default libRadtran profile [22]. LIVAS extinction coefficient profiles were interpolated to the coordinates of three Mediterranean sites: Cairo $\left(31.2^{\circ} \mathrm{E}, 30.0^{\circ} \mathrm{N}\right)$, Lampedusa $\left(12.6^{\circ} \mathrm{E}, 35.5^{\circ} \mathrm{N}\right)$, and Athens $\left(23.7^{\circ} \mathrm{E}, 37.6^{\circ} \mathrm{N}\right)$. The (normalized) profiles corresponding to $532 \mathrm{~nm}$ AOD $>0.8$ were averaged for the period $2006-2018$ and used for the RT simulations. Visual inspection of the profiles and back-trajectory analyses of air masses from the HYSPLIT model (https://www.ready.noaa.gov/HYSPLIT.php) revealed that high AOD was in all cases related with strong dust events. RT simulations were performed assuming typical optical 
properties for dust-dominated aerosol mixtures (AE=0.3 and SSA: $0.8,0.85,0.95,0.98$ for UVB, UVA, VIS, and NIR respectively) $[17,73]$ and $550 \mathrm{~nm} \mathrm{AOD}=1$. In addition to the aerosol optical properties, other model inputs were the annual averages of TCWV, TCO, and surface albedo. The latter quantities were derived from the sources described in section 2.4 for the period 2006 - 2018. Climatological annual averages were calculated and used for the simulations. RT simulations were repeated for the same conditions using the default libRadtran extinction coefficient profile [22], instead of the LIVAS profiles. The input parameters for UVSPEC are listed in Table 5.

Table 5: TCO, TCWV, surface albedo and aerosol optical properties (AOD at $550 \mathrm{~nm}, \mathrm{SSA}, \mathrm{AE}$ ) used in the simulations for Cairo, Lampedusa and AthensAOD at $550 \mathrm{~nm}$ used in the simulations.

\begin{tabular}{ccccccc}
\hline & $\begin{array}{c}550 \mathrm{~nm} \\
\text { AOD }\end{array}$ & SSA & AE & TCWV $(\mathrm{mm})$ & TCO (DU) & $\begin{array}{c}\text { Surface } \\
\text { albedo }\end{array}$ \\
\hline \multicolumn{7}{c}{ Cairo } \\
\hline UVB & 1 & 0.80 & 0.3 & 16.6 & 295 & 0.05 \\
UVA & 1 & 0.85 & 0.3 & & & 0.05 \\
VIS & 1 & 0.95 & 0.3 & & & 0.11 \\
IR & 1 & 0.98 & 0.3 & & 0.11 \\
\hline \multicolumn{7}{c}{ Lampedusa } \\
\hline UVB & 1 & 0.80 & 0.3 & 20.3 & 312 & 0.05 \\
UVA & 1 & 0.85 & 0.3 & & & 0.05 \\
VIS & 1 & 0.95 & 0.3 & & & 0.08 \\
IR & 1 & 0.98 & 0.3 & & 0.08 \\
\hline & 1 & 0.80 & 0.3 & 18.5 & 0.05 \\
\hline UVB & 1 & 0.85 & 0.3 & & 0.05 \\
UVA & 1 & 0.95 & 0.3 & & 0.11 \\
VIS & 1 & 0.98 & 0.3 & & 0.11 \\
IR & 1 & &
\end{tabular}

\section{Results and discussion}

\subsection{Altitude of the aerosol layer}

As described in Section 2.3, the magnitude of the differences in the vertical radiation profiles when the altitude of the aerosol layer changes was investigated using artificial aerosol extinction profiles. Relative differences [\%] were calculated between simulations for which all parameters were the same, except the aerosol extinction coefficient profile. The radiation profiles for elevated aerosol layers $(\mathrm{L} 1, \ldots, \mathrm{L} 4)$ were compared with the radiation profiles for L0. L0 was used as a reference because it is closer to commonly used climatological profiles, as most of the radiation extinction by aerosols takes place near the surface. Sensitivity of the results to different TCWV was found to be very small even in the NIR (although the profile of NIR changes significantly for different values of the $\mathrm{TCWV}$ ). Thus, only results for TCWV $=10 \mathrm{~mm}$ are presented. Moreover, sensitivity analysis that was performed prior to the simulations revealed that the effect of changes in TCO (within realistic limits) on the results is also negligible. Therefore, all simulations were performed for $\mathrm{TCO}=350 \mathrm{DU}$.

The differences for different radiometric quantities (DI, GI, DDI, UDI, and AF) and spectral regions (UVB, UVA, VIS, and NIR) are presented in Figures 3 and 4 . The presented results are for $\mathrm{AOD}=1, \mathrm{SZA}=60^{\circ}$, surface albedo $=0.1, \mathrm{TCWV}=10 \mathrm{~mm}$, and two values of the SSA: 0.75 and 0.95 . The results for the DDI are presented in an independent figure (Figure 4) because of the different scale relative to other quantities. Results for different AOD (0.2 and 0.5), surface albedo (0.8), and SZAs $\left(20^{\circ}\right.$ and $\left.80^{\circ}\right)$ are presented in Appendix A and are discussed in the present section. 


\subsubsection{Direct irradiance}

In line with the radiative transfer theory basics, changing the altitude of the layer has the same effect on the DI at all four spectral regions because attenuation of DI depends solely on the AOD which has been assumed to be constant at all spectral bands. When simulations are performed with aerosol layer at a higher altitude instead of $\mathrm{L} 0$, then the DI gradually decreases from the top to the bottom of the elevated layer, while the difference with respect to the irradiance for L0 gradually increases (up to $~ 86 \%$ at the bottom of the elevated layers when the layer base is higher than the top of L0). Then, at the top of L0 the differences gradually tend to zero, and finally there is no change in the amount of the DI that reaches the surface. Decreasing/increasing the SZA or the AOD for the simulations leads to smaller/larger differences in DI between the layers (Figures A1 - A5). The results for DI are independent from the changes in SSA and surface albedo.

\subsubsection{Diffuse downwelling and upwelling irradiances}

Changes in diffuse irradiance strongly depend on solar spectral region and the SSA. The presence of aerosols leads to increased scattered (downwelling and upwelling) irradiance relative to aerosol-free atmosphere. Additional scattering and absorption of solar radiation with respect to aerosol-free atmosphere takes place inside the layer of aerosols and also affects the distribution of photons above and below the layer.

\begin{tabular}{|c|c|c|c|}
\hline$L 1, S S A=0.95$ & L2,SSA=0.95 & $\longrightarrow$ L3,SSA $=0.95$ & $\longrightarrow$ L4,SSA $=0.95$ \\
\hline L1,SSA $=0.75$ & $\mathrm{~L} 2, \mathrm{SSA}=0.75$ & $\ldots$ & L4,SSA $=0.75$ \\
\hline
\end{tabular}
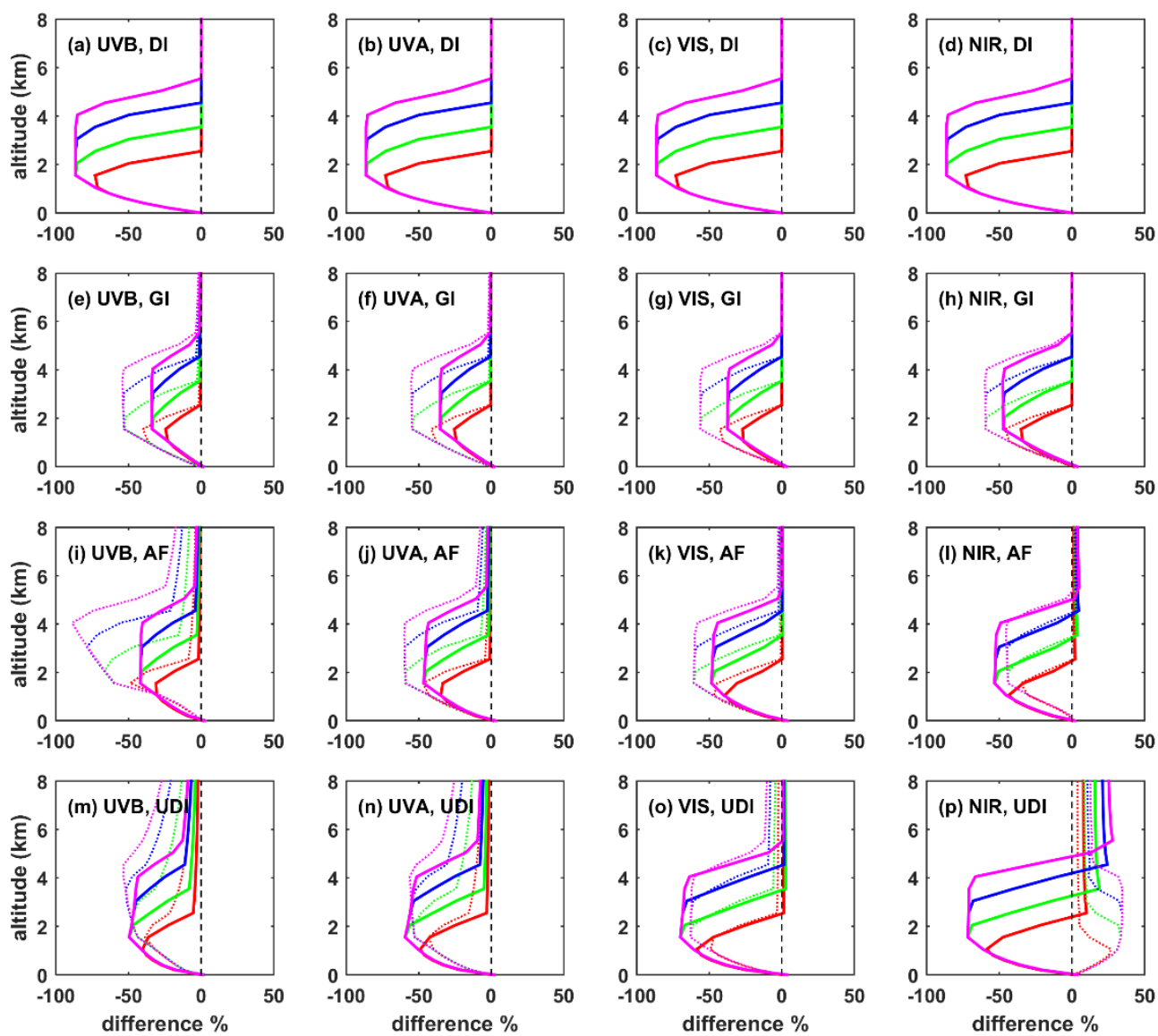

Figure 3. Change (in \%) in the profiles of DI (first row), GI (second row), AF (third row), and UDI (fourth row) in UVB (first column), UVA (second column), VIS (third column), and NIR (fourth column). The presented results are for $\mathrm{AOD}=1, \mathrm{SZA}=60^{\circ}$, surface albedo $=0.1, \mathrm{TCWV}=10 \mathrm{~mm}$, and two values of the SSA: 0.75 (dotted lines) and 0.95 (solid lines). 

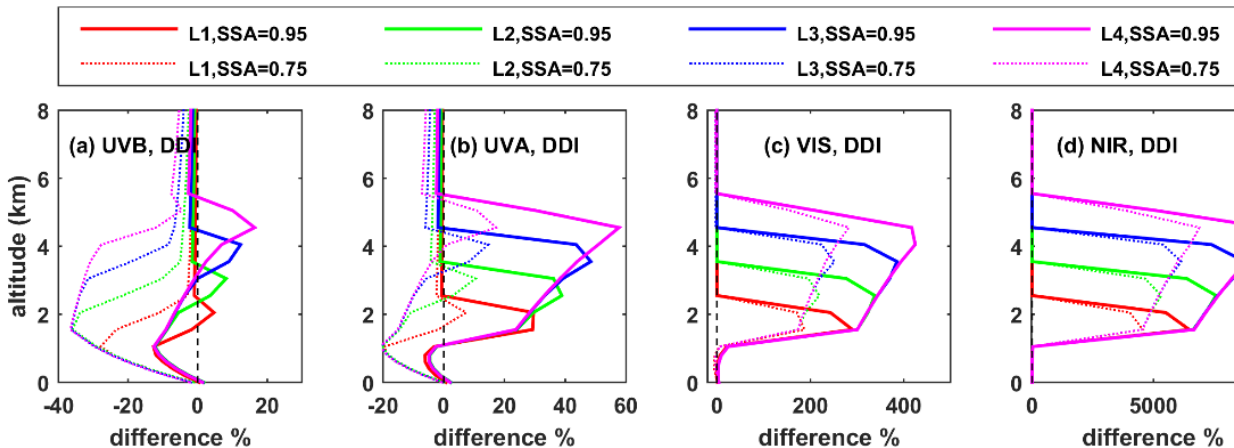

Figure 4. Change (in \%) in the profiles of DDI in UVB, UVA, VIS, and NIR. The presented results are for $\mathrm{AOD}=1, \mathrm{SZA}=60^{\circ}$, surface albedo $=0.1, \mathrm{TCWV}=10 \mathrm{~mm}$, and two values of the SSA: 0.75 (dotted lines) and 0.95 (solid lines).

Downwelling diffuse irradiance

For scattering aerosols $(\mathrm{SSA}=0.95)$ the increase of the DDI due to the presence of an elevated aerosol layer (with respect to the corresponding DDI for L0) begins at the top of the layer and becomes maximum near the middle of the layer. Maximum difference is larger for L4 and gradually becomes smaller for lower-altitude layers. In an aerosol-free atmosphere the DDI would increase with decreasing altitude. Rayleigh scattering is more intense for shorter wavelengths. At UVB wavelengths the diffuse component of the downwelling irradiance is already strong between 4 and $5.5 \mathrm{~km}$ even in an aerosol-free atmosphere, while at NIR wavelengths there is nearly zero DDI at the same altitude under the same conditions. Thus, the same absolute increase in DDI due to the presence of aerosols would lead to much larger relative increase for NIR relative to UVB. For example, for L4 maximum increase is $\sim 10 \%$ for UVB and $\sim 10000 \%$ for IR. The relative increase gradually becomes weaker below about the middle of the elevated aerosol layer. Below $1 \mathrm{~km}$, UVA DDI for elevated aerosol layers is smaller with respect to the DDI for L0 (for SSA=0.95). For UVB differences in DDI (DDI for an elevated aerosol layer - DDI for L0) switch from positive to negative at a distance of a few hundreds of meters below the base of the elevated aerosol layer.

When aerosols are more absorbing (SSA=0.75), the magnitude of differences between the DDI for elevated aerosol layers and the DDI for L0 is in all cases smaller compared to more scattering aerosols (SSA=0.95). In UVA the DDI is larger at the altitude of the elevated layer and smaller in the rest of the atmosphere, while in UVB the DDI is smaller even at the altitude of the elevated aerosol layer. This is because absorption of the scattered irradiance coming from Rayleigh scattering dominates over excessive scattering by aerosols when aerosols are at higher altitude relative to L0. It is interesting that in UVB and UVA DDI decreases also above the elevated aerosol layers, with the decrease being larger for more elevated layers (i.e., maximum for L4). This is because when the layer of aerosols is higher it absorbs more photons before they interact with the denser atmosphere below the layer. If the layer was lower (e.g., L0 instead of L4), part of these photons would be backscattered before entering the layer of aerosols. In simple words, more photons interact with aerosols, and subsequently more photons are absorbed, when the layer is higher. Part of the photons absorbed in the elevated layer would have been anyway absorbed in L0. However, another part would have been backscattered towards the TOA. Differences in the number of photons that reach the surface are in both cases smaller leading to differences of a few percent at the BOA.

Decreasing the AOD suppresses the differences without changing their direction (Figures A6 and A7). Changing the SZA however can also have an impact on the direction of the differences, leading to "less positive" differences for larger SZAs (Figures A8 and A9). When the surface is highly reflective (e.g., surface albedo $=0.8$, Figure A10) the differences are slightly more positive (by $\sim 5-10 \%$ ) for UVB and UVA relative to those for surface albedo $=0.1$, for altitudes between the bottom of the elevated layer and the BOA. 
Inside and above the elevated layer differences are much smaller with respect to the corresponding lower surface albedo cases. This is possibly because the aerosol layer and the reflective terrain enhance the scattering toward the BOA (the former) and the TOA (the latter) leading to increased number of photons between the aerosol layer and the surface. At VIS and NIR wavelengths this effect is minor relative to UVB and UVA because of the less efficient scattering by air molecules, and the corresponding differences (for high and low surface albedo) are very small.

\section{Upwelling diffuse irradiance}

At NIR wavelengths the scattered irradiance in the atmosphere is negligible in the absence of aerosols. Thus, adding a layer of aerosols leads to more UDI inside and above the layer. Increasing the altitude of the layer leads to more UDI at the TOA as the scattered photons have less chances to interact with absorbing gasses (mainly water vapor). Thus, when comparing the UDI profiles for elevated layers (L1, .., L4) and L0 the difference is always positive above about the mid of the elevated layer. For SSA $=0.95$ the difference is negative below the mid of the layer, while for SSA $=0.75$ it is positive, which means that the NIR UDI increases between the elevated aerosol layer and the BOA. For scattering aerosols it is easy to understand that when the layer is lower, there is more UDI at lower altitudes. However, when absorbing aerosols are low in the atmosphere (L0), it is possible that combined absorption of the NIR by gasses and aerosols is stronger than the absorption when aerosols are higher in the atmosphere. This is because, at the SZA of $60^{\circ}$ part of the photons which have been scattered at a higher altitude go through shorter optical paths (relative to being scattered near the surface) because they move "more vertically" in the atmosphere. Thus, they have less chances to get absorbed, and more chances to be reflect toward the TOA. It is possible that the combination of the two phenomena described above leads to more NIR UDI when the aerosol layer is higher. This is not however the case for different SZAs (e.g., $\mathrm{SZA}=20^{\circ}$ or $\mathrm{SZA}=80^{\circ}$ ) for which the differences in NIR UDI are negative below the elevated layer, even for absorbing aerosols (Figures A3 and A4). For SZA smaller than $60^{\circ}$, that happens because the difference in the path of the photons does not change as significantly as for $\mathrm{SZA}=60^{\circ}$. For $\mathrm{SZA}=80^{\circ}$, the attenuation of the NIR irradiance in the aerosol layer is so strong that differences below the layer are again negative. Very high surface albedo (e.g., surface albedo $=0.8$ ) leads to increased UDI below the base of elevated aerosol layers (compared to UDI at the same altitudes for aerosols at L0) even for SSA=0.95 (Figure A5). This is possibly because many NIR photons are reflected at the surface (towards the aerosol layer) and then scattered in the layer (towards the surface), and this process is repeated multiple times for part of the photons.

Absorption of the UVB, UVA and VIS radiation in the troposphere is generally weak (under usual conditions) with respect to absorption of the NIR radiation. Aerosols at any altitude enhance the UDI inside and above the layer. As the altitude of the layer increases it absorbs and scatters back to the surface part of the UDI that enters the base of the layer from below. Thus, for UVB, UVA, and VIS, an elevated aerosol layer results to less UDI above, inside, and below the elevated layer with respect to the UDI inside and above L0. The differences are more significant above the elevated layer for more absorbing aerosols. For SSA $=0.95$ the absolute differences increase gradually from the top to the bottom of the elevated layer, then remain relatively stable between the base of the elevated layer and the top of L0 and again decrease until the surface. For UVB and UVA (where Rayleigh scattering is more intense relative to VIS) when SSA $=0.75$ the absolute difference is maximum inside the aerosol layer and then decreases (faster below the top of L0) until the surface. Decreasing the AOD suppresses the differences (Figures A1 and A2) without however significantly changing their relative distribution in the atmosphere. Similarly, changing the SZA (Figures A3 and A4) affects mainly the magnitude of the decrease.

When an elevated aerosol layer is above very reflective terrain, enhanced multiple scattering leads to significant increase of the UDI between the layer and the surface (especially at shorter wavelengths). Increasing the altitude of the layer reduces the UDI above 
the layer with respect to aerosol-free atmosphere, more than it does over low-albedo terrain. The latter reduction becomes stronger as the absorption efficiency of the aerosol layer increases. Thus, comparing UDI for an elevated aerosol layer with UDI for L0 (Figure A5) results to positive differences between the bottom of the elevated layer and the surface. For UVB and UVA, differences are negative above the altitude of the bottom of the elevated aerosol layer. They become more negative with increased absorption efficiency of the aerosols and increased altitude of the layer. For VIS, differences are (like for IR) positive even above the altitude of the bottom of the elevated layer.

\subsubsection{Global irradiance}

The global irradiance (GI) is the summary of the DI and the DDI. Thus, differences due to changes in the altitude of the aerosol layer depend on the differences in DI and DDI, and on the contribution of each component to the GI. The contribution of DI is more significant for longer relative to shorter wavelengths (because longer wavelengths are scattered less effectively by air molecules) and becomes more significant as SZA decreases. In the UVB region the diffuse component of the downwelling irradiance is already very strong in the GI at $60^{\circ}$, even above the aerosol layer. As wavelength increases the relative contribution of the direct component becomes more significant, and for the NIR the direct component becomes dominant. Thus, despite the very large differences between different spectral regions regarding the effect of altitude on DDI, the results for GI are very similar. For SSA $=0.95$ the differences between the bottom of the elevated layer and the top of $\mathrm{L} 0$ are $-35--45 \%$, while for SSA $=0.75$ the corresponding differences are about $60 \%$. Changing the AOD, the SZA or the surface albedo (Figures A1 - A5) affects the absolute differences, but not their direction or distribution. However, at very high SZAs the absolute differences are larger (in percent) for larger wavelengths (Figure A4), but they correspond to low absolute GI values.

\subsubsection{Actinic flux}

Increasing the altitude of the aerosol layer leads to decreased actinic flux between the elevated layer and L0. As for GI the decrease is constant between the top of L0 and the bottom of the elevated layer and does not depend on the altitude of the elevated layer unless its bottom is below the top of L0. At SZA $=60^{\circ}$ and for SSA $=0.95$ and surface albedo $=0.1$, the decrease is $\sim 40 \%$ for UVB and becomes larger with increasing wavelength, up to $\sim 55 \%$ for NIR. At the same conditions but for SSA $=0.75$ the decrease is larger for UVB $(\sim 60 \%)$ and becomes smaller for increasing wavelength (it is $\sim 45 \%$ for NIR). As the SZA increases the effect of changing altitude of the aerosol layer becomes more significant for longer wavelengths. For example, at $80^{\circ}$ the differences between the bottom of the elevated aerosol layer and the top of L0 are of the order of $-90 \%$ for NIR, while for UVB they are similar to the differences for $60^{\circ}$ (Figure A4). Over high albedo surfaces the effect of changing altitude of the aerosol layer is less significant (compared to the same changes over low albedo surface), especially for highly scattering aerosols (Figure A5). As discussed earlier, this is because increasing the altitude of the aerosol layer leads to decreased DI but at the same time to increased diffuse irradiance below the layer (with respect to what happens at the same altitudes in the atmosphere for aerosols at L0).

\subsubsection{Heating rates}

Differences in HR depict differences in the net flux of irradiance (i.e., the difference between the ingoing and the outgoing irradiance at a specific altitude). In the absence of aerosols this quantity is very small (below $0.1 \mathrm{~K} /$ day) for the $\mathrm{SW}$ radiation, which explains the very large differences presented in Figure 5. Changes in UVB and UVA play a minor role in the overall changes in the HR of the SW irradiance and the main contribution comes from radiation in the VIS and NIR regions. Thus, changes in the HR for the total SW radiation are discussed in this section. 
HR increase significantly inside, and a few hundreds of meters above and below, the elevated aerosol layers and decreases below the layers with respect to the heating rate for L0 (Figure 5). The increase inside the layer is very large, while the decrease below the layer gradually reaches values between $90 \%$ and $100 \%$ at the altitude of $1.5 \mathrm{~km}$ (i.e., the top of L0). The increase inside the layer becomes larger as the layer altitude increases, and further increases for more absorbing aerosols and larger SZA. Increasing the surface albedo leads to very small changes (small suppression of the differences) in the results.
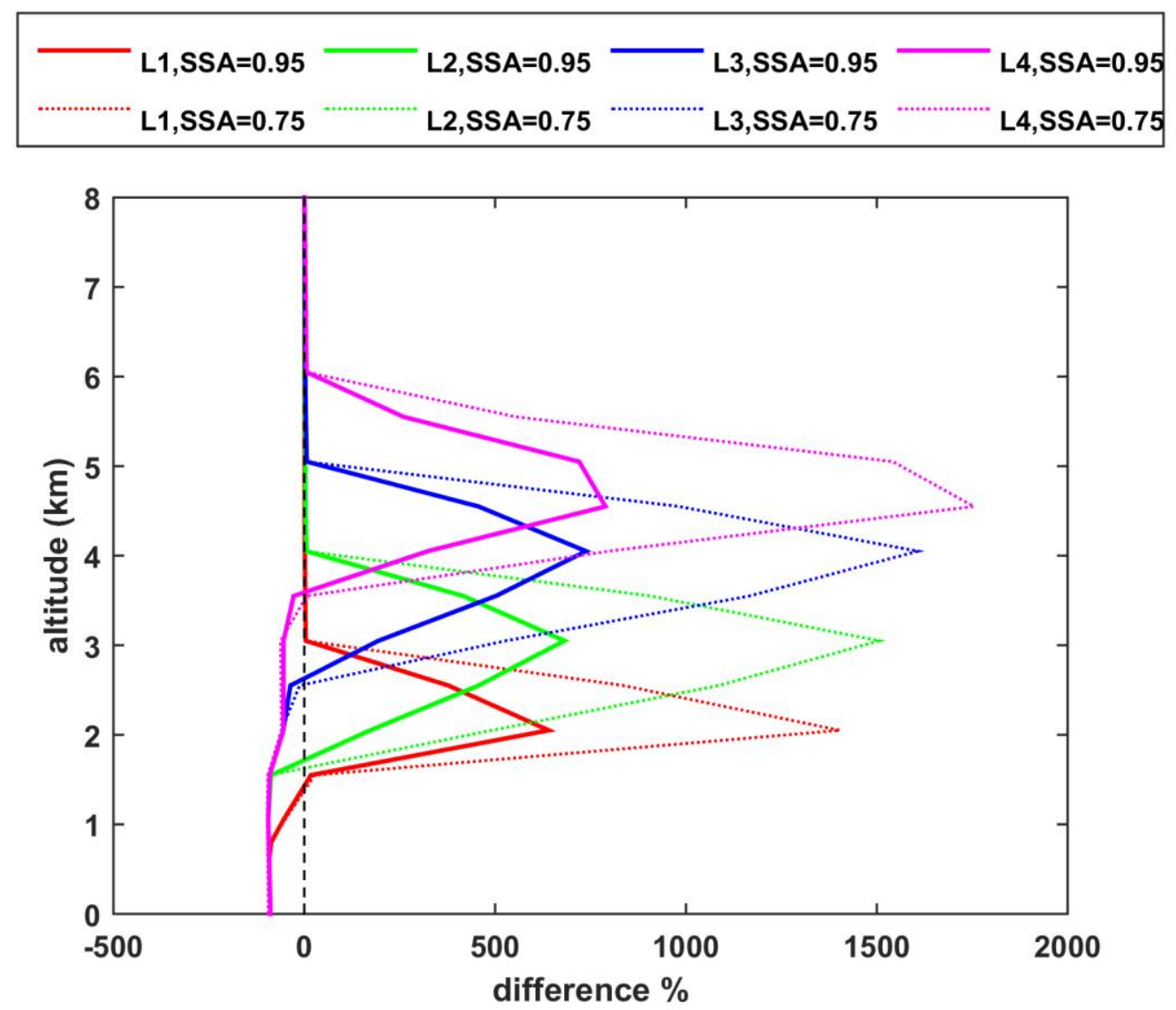

Figure 5. Change (in \%) in the profiles of $\mathrm{HR}$ for $\mathrm{SW}$ radiation. The presented results are for AOD = $1, \mathrm{SZA}=60^{\circ}$, surface albedo $=0.1$, water vapor $=10 \mathrm{~mm}$, and two values of the SSA: 0.75 (dotted lines) and 0.95 (solid lines).

\subsubsection{Top and bottom of the atmosphere}

In most climatic studies, default aerosol profiles are used which commonly assume exponential decrease of aerosol extinction (with aerosols concentrated in the first 1-2 km from the surface). In many cases this assumption does not affect the modelled irradiance at the BOA and the TOA significantly (e.g., [23]). However, as shown in the following section for high aerosol loads and under certain conditions (e.g., high SZA or high surface albedo, aerosol layers at very high altitudes) this assumption can result to non-negligible errors in the simulations of the GI at the BOA or the UDI at the TOA when large fraction of the aerosols is located at higher altitudes (e.g., at 3 or $4 \mathrm{~km}$ ). In this section, the effect of the altitude of the aerosol layer on GI, at the surface, and UDI at the TOA are discussed for $A O D=1$. 


\begin{tabular}{|llllllll|}
\hline$\circ$ & L1,SSA $=0.75$ & $\bigcirc$ & L3,SSA $=0.75$ & $\times$ & L1,SSA $=0.95$ & $\times$ & L3,SSA $=0.95$ \\
$\circ$ & L2,SSA $=\mathbf{0 . 7 5}$ & $\bigcirc$ & L4,SSA $=0.75$ & $\times$ & L2,SSA $=0.95$ & $\times$ & L4,SSA $=0.95$ \\
\hline
\end{tabular}
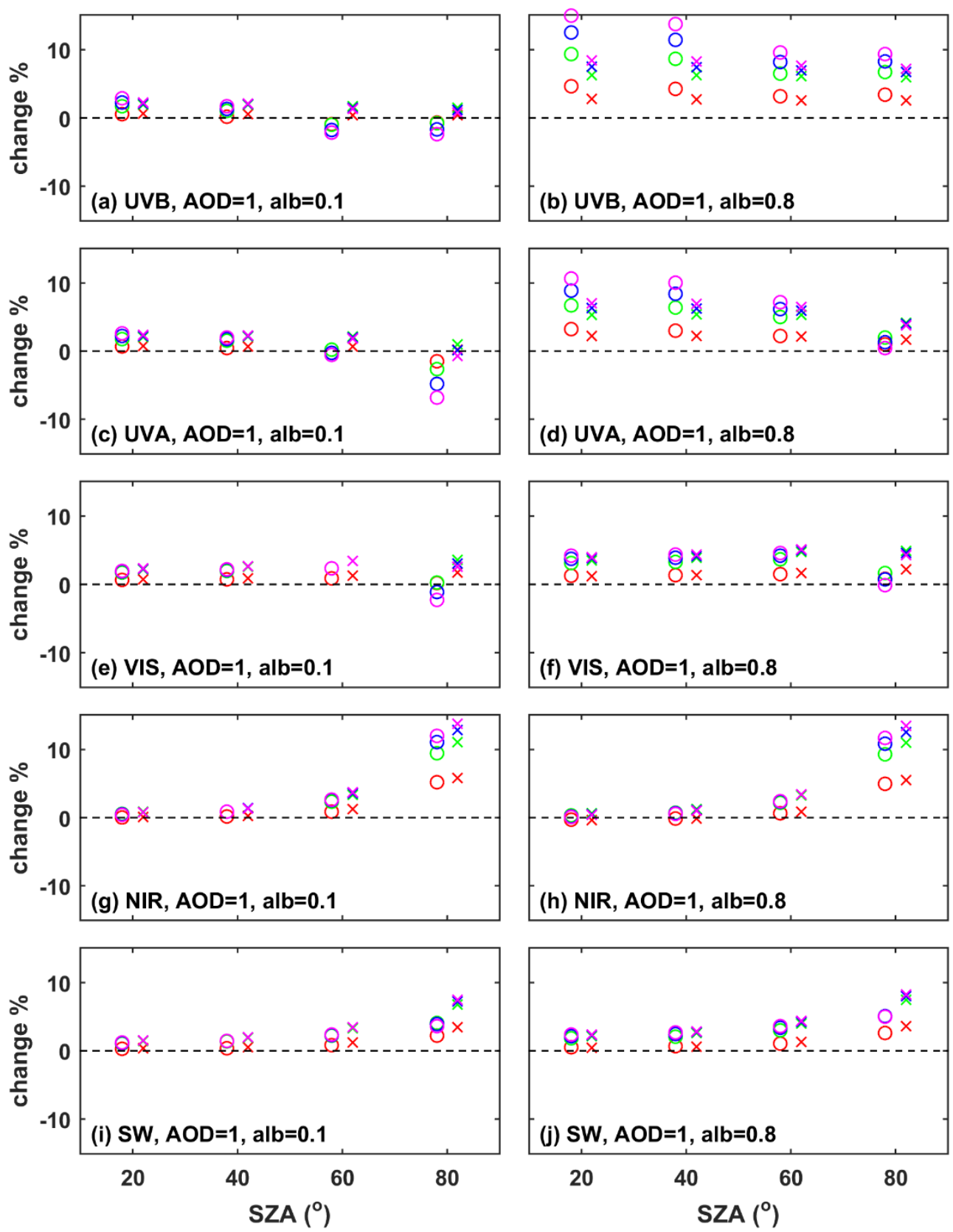

Figure 6. Relative differences in GI at the BOA for different altitudes of the elevated aerosol layer, SSA and surface albedo with respect the corresponding conditions when aerosols are at L0 (elevated layer - L0). The presented results are for AOD $=1$ and TCWV $=10 \mathrm{~mm}$. Different rows represent different spectral regions (UVB, UVA, VIS, NIR). Different columns represent different surface albedo (left: 0.1 , right: 0.8 ).

\section{BOA}

Differences (in \%) of the GI for the four spectral bands as it was simulated for aerosols at higher altitudes (L1, ..., L4) and aerosols at L0 are presented in Figure 6. Below SZA $=60^{\circ}$ and for low surface albedo the altitude of the aerosol layer has small impact on the GI that reaches the surface since differences are in all cases below $5 \%$. For SZA $=80^{\circ}$ the differences are larger, up to $15 \%$, mainly for UVA and NIR. For UVA, increasing the altitude of the layer leads to increased absorption by absorbing $(S S A=0.75)$ aerosols. For $\mathrm{L} 4$ the reduction is nearly $8 \%$ with respect to the UVA at the BOA for L0. A possible explanation is that the 
direct beam that enters L0 is significantly weaker than the direct beam that enters L4. At such large SZA the optical path inside the layer is longer for photons of the direct beam relative to scattered photons. Thus, when aerosol layer is higher, absorption of UVA irradiance by aerosols is stronger. For UVB the corresponding reduction is smaller because at high SZA (above $60^{\circ}$ ) the contribution of the direct component is already weak relative to the contribution of the scattered component of GI at $5.5 \mathrm{~km}$. In the VIS and NIR regions, although the direct component is stronger than in UV, the photons are scattered less effectively in the atmosphere. Thus, in aerosol-free skies the direct component of VIS and NIR GI is similar at $1.5 \mathrm{~km}$ and $5.5 \mathrm{~km}$. In NIR the GI at the BOA at SZA=80 increases with increasing altitude of the aerosol layer (by $12-14 \%$ for L4), for both, absorbing and reflective aerosols. This is possibly because scattering of the NIR at higher altitude at such large SZA results to reduced optical path for a significant fraction of the scattered photons as they propagate "more vertically" below the aerosol layer moving towards the surface and are thus absorbed less effectively by atmospheric molecules (mainly by water vapor).

The altitude of the aerosol layer plays a more significant role over highly reflective surfaces, especially when Rayleigh scattering is strong (i.e., in the UVB and UVA regions). The global irradiance at BOA increases with increasing aerosol layer altitude, by up to $15 \%$ in the UVB for L4 and small SZA. When the layer of aerosols is inside denser atmosphere (i.e., near the surface) the photons follow longer paths in the layer (due to multiple Rayleigh scattering) with respect to elevated aerosol layers. This phenomenon is intensified over reflective surfaces due to multiple interactions of the photons with the surface, the dense atmosphere, and the aerosol particles. If the layer constitutes from absorbing aerosols, then increased absorption leads to even larger differences between GI at the BOA for elevated aerosol layers and L0, up to $15 \%$ for L4. Longer wavelengths are scattered less effectively in the atmosphere, which is the reason for the very small (below 3\%) differences between Figures 6(e) and 6(f) (for reflective and absorbing aerosols). Rayleigh scattering in the NIR is negligible, thus the corresponding differences between panels $6 \mathrm{~g}$ and $6 \mathrm{~h}$ are nearly zero.

Changes in total irradiance (panels 6i and 6j) due to different altitude of the aerosol layer are determined by changes in the VIS and the IR. For increasing altitude of the aerosol layers the total GI at BOA increases. The increase is smaller than $5 \%$ for SZAs below $60^{\circ}$ and larger for $\mathrm{SZA}=80^{\circ}$. The increase is similar for L2, L3, and L4, of $7-8 \%$. Changing the surface albedo has negligible impact on total GI at the BOA. It must be mentioned that in realistic conditions the $\mathrm{AE}$ is larger than 0 and subsequently the effect of aerosols is larger at shorter wavelengths, which means that the contribution of changes in the NIR on the changes of the total GI would be less significant than the contribution of NIR in the results presented in panels $6 \mathrm{i}$ and $6 \mathrm{j}$. 


\begin{tabular}{|llllllll|}
\hline$\circ$ & L1,SSA $=\mathbf{0 . 7 5}$ & $\bigcirc$ & L3,SSA $=\mathbf{0 . 7 5}$ & $\times$ & L1,SSA $=0.95$ & $\times$ & L3,SSA $=0.95$ \\
$\circ$ & L2,SSA $=\mathbf{0 . 7 5}$ & $\bigcirc$ & L4,SSA $=\mathbf{0 . 7 5}$ & $\times$ & L2,SSA $=0.95$ & $\times$ & L4,SSA $=0.95$ \\
\hline
\end{tabular}
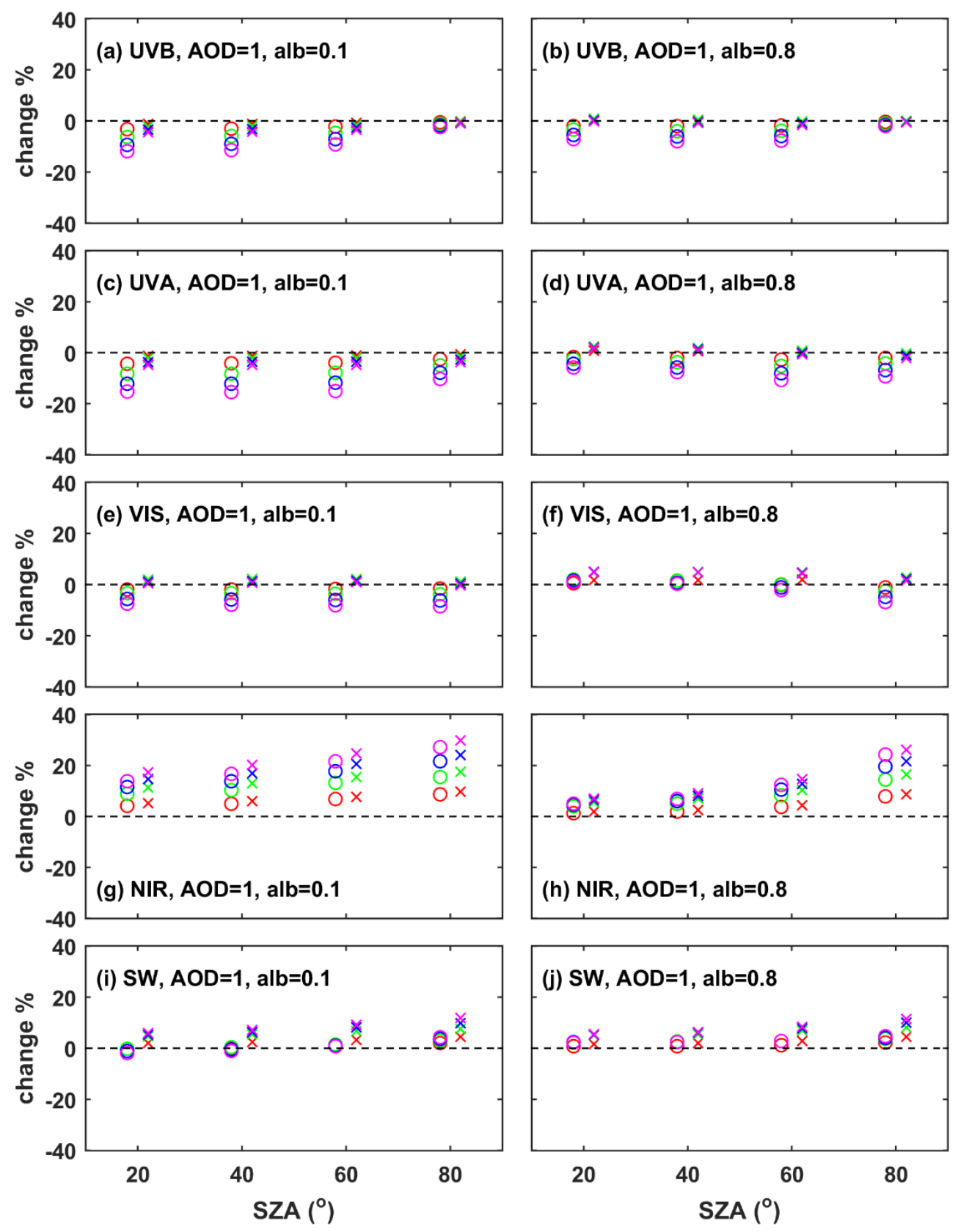

Figure 7. Change (in \%) in the UDI at the TOA (realistic - default) for different altitudes of the aerosol layer, SSA and surface albedo. The presented results are for AOD $=1$ and TCWV $=10 \mathrm{~mm}$. Different rows represent different spectral regions (UVB, UVA, VIS, IR). Different columns represent different surface albedo (left: 0.1, right: 0.8).

TOA

As shown in Figure 7, changing the altitude of the aerosol layer has very small impact on UDI in UVB, UVA, and VIS at the TOA when aerosols are highly scattering (SSA=0.95). In all these cases differences in the UDI are well below $5 \%$ for different aerosol layer altitudes. This is not the case however for NIR that differences in the UDI increase with increasing altitude of the aerosol layer. In the latter case the magnitude of increase depends on surface albedo and SZA and reaches $33 \%$ for L4 and surface albedo=0.1. For UVB, UVA, and VIS, aerosols (with SSA $=0.95$ ) play a role that is similar to that of the atmospheric molecules: they scatter and redistribute photons. Thus, the altitude of the aerosol layer 
does not play a very significant role regarding the UDI that exits in the atmosphere. In contrast, NIR is scattered weakly by atmospheric molecules and is mainly absorbed by water vapor. NIR radiation is however scattered by aerosols. Part of the scattered NIR radiation is then moving towards the TOA. When the aerosol layer is higher, absorption of the upwelling NIR by water vapor is weaker (due to the smaller optical path) and more UDI reaches the TOA. This effect is weaker over highly reflective terrain and small SZAs (panel 7h) because in such cases NIR that has been reflected at the surface constitutes significant fraction of the UDI.

For absorbing aerosols (SSA=0.75), the results for the NIR are similar with the results for scattering aerosols (SSA=0.95). However, absorbing aerosols induce more significant differences in UVB, UVA and VIS relative to scattering aerosols. When aerosols are low in the atmosphere (i.e., L0) the backscattered photons (due to Rayleigh scattering) at altitudes above $1.5 \mathrm{~km}$ do not interact with aerosols. However, if the aerosol layer is higher, then backscattered photons coming from higher altitudes in the troposphere will also interact with aerosols and part of them will be absorbed. Thus, increasing the altitude of the aerosol layer leads to reduced UDI at the TOA. Over highly reflective terrains the UDI also constitutes from photons which have been reflected by the earth surface. The altitude of the layer does not significantly affect the amount of the latter photons that reach the TOA. Thus, the decrease is weaker for surface albedo $=0.8$ relative to surface albedo $=0.1$.

Although for different spectral regions changing the altitude of the layer may induce large differences in the UDI at the TOA, differences are generally below $15 \%$ for total UDI. Total UDI increases with increasing altitude of the aerosol layer, mainly for reflective aerosols. As in the previous section it should be mentioned again that in realistic conditions Angstrom Exponent is above zero, which means that the results for total UDI would be closer to the results for VIS compared to the results presented in panels $7 \mathrm{i}$ and $7 \mathrm{j}$.

\subsection{Effect of extinction coefficient profile for typical aerosol conditions}

The methodology used in this section has been described in Section 2.4. The differences between the seasonal total-aerosol extinction coefficient (at $532 \mathrm{~nm}$ ) profiles from LIVAS and the libRadtran default profile [22] (both scaled to the seasonally averaged AOD at $350 \mathrm{~nm}$ ) for the two regions are presented in Figure 8.
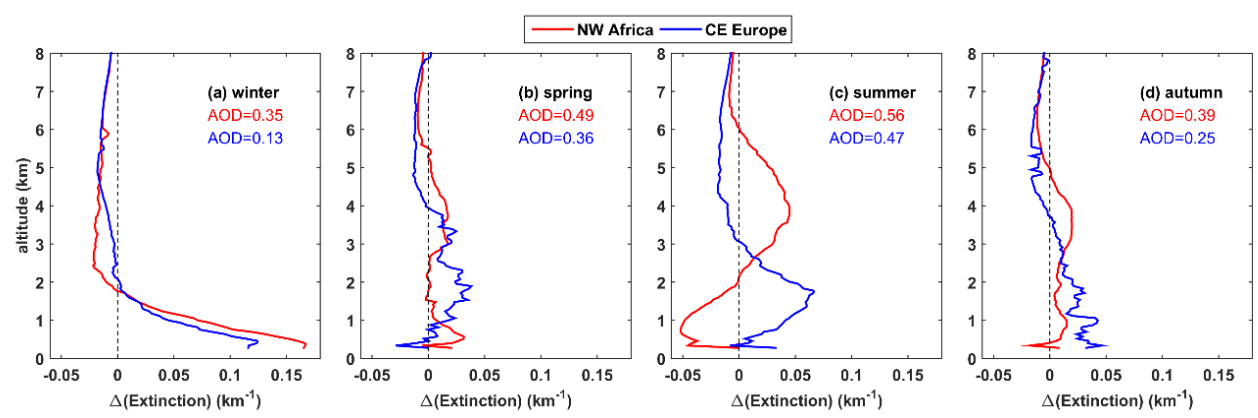

Figure 8. Differences between the LIVAS and the libRadtran default extinction coefficient profiles for the AOD at $350 \mathrm{~nm}$. The results are shown for CE Europe (blue line) and NW Africa (red line) for the four seasons of the year. The $350 \mathrm{~nm}$ AOD for each is also shown in the panels with the corresponding colors. 

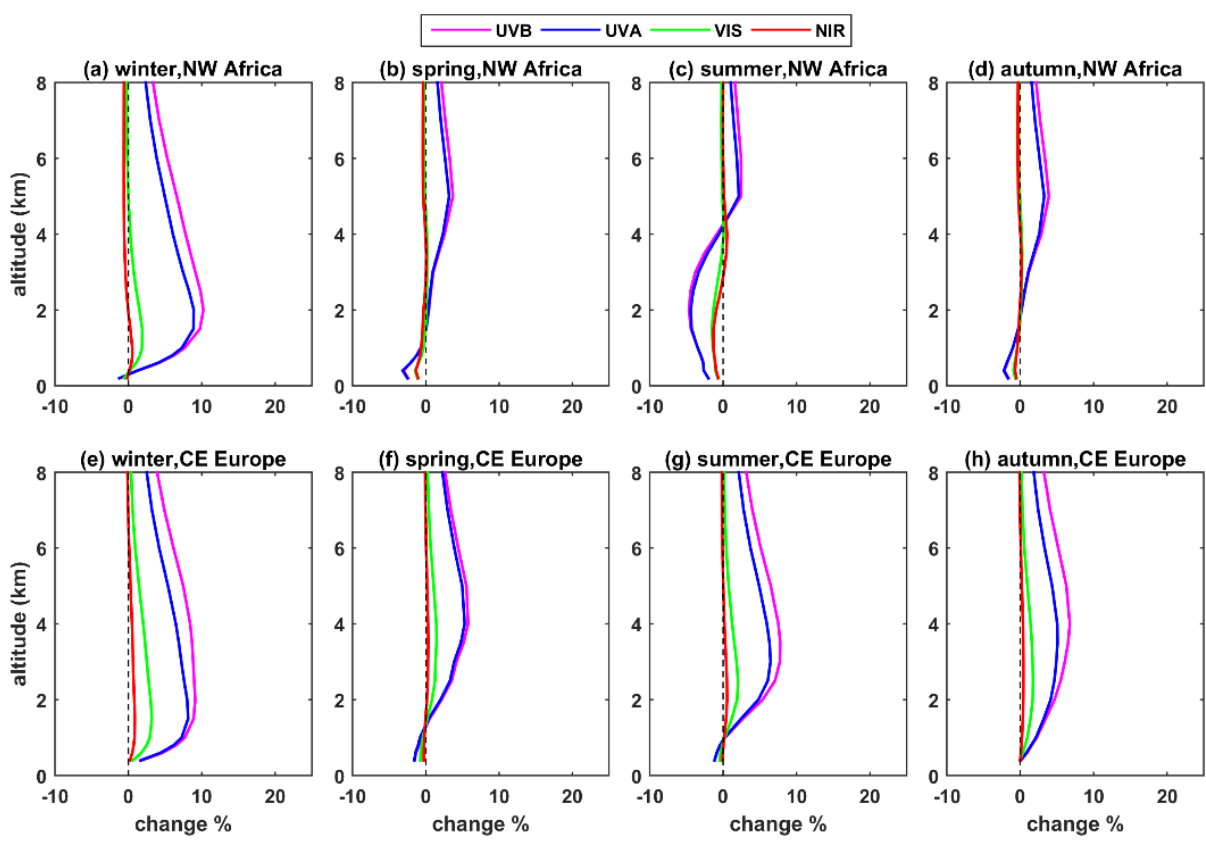

Figure 9. Change (in \%) in the AF in the first $8 \mathrm{~km}$ of the atmosphere due to the use of the LIVAS profiles instead of the default libRadtran profile. Results are for $\mathrm{SZA}=60^{\circ}$. The corresponding graphs for $30^{\circ}$ and $80^{\circ}$ are provided in the supplement.

The different characteristics of aerosols over the two regions lead to quite different patterns in the extinction coefficient profile differences. Over CE Europe continental aerosols constitute a significant fraction of the aerosol mixture, while over NW Africa dust plays a very significant role. The differences in the vertical profiles of the AF are presented in Figure 9. In all cases shown in Figure 9, differences are much larger in the UVB and UVA regions relative to VIS and NIR, mainly because the AOD increases with decreasing wavelength, and thus differences in the extinction coefficient profiles become larger. Given that differences in the VIS and NIR AF are very small, the results are discussed only for UVB and UVA in the following. As expected, differences in AF at the BOA are in all cases small, below $3 \%$.

In winter, for both areas, aerosol extinction is underestimated below $\sim 1.5 \mathrm{~km}$ and overestimated above the same altitude when the default profile is used for the simulations. Thus, the patterns of differences in AF profiles are similar for the two regions. For UVB and UVA maximum increase of the order of $10 \%$ was found between 1.5 and $2 \mathrm{~km}$. Less scattering and absorption by aerosols above $1.5 \mathrm{~km}$ allows to more photons that are moving towards the surface to reach the specific altitude. At the same time excessive scattering by aerosols near the surface leads to more upwelling photons at the altitude of 1.5 $\mathrm{km}$. Thus, the increase is maximum at the particular level.

For CE Europe, the pattern of differences between the default and the measured vertical profile of aerosol extinction coefficient is the following: Negative differences (i.e., overestimation by the default profile) above an altitude which ranges from $\sim 2 \mathrm{~km}$ in winter to $\sim 4 \mathrm{~km}$ in spring. Then, differences become positive. In spring and summer, differences approach zero near the surface. For the reasons discussed above, for all seasons, the corresponding differences in UVB and UVA AF are maximum near the altitude of change from negative to positive differences in aerosol extinction coefficient. Maximum differences in AF are small, of $5-10 \%$, while near the surface the differences are even smaller, below $5 \%$.

For NW Africa there is a stronger seasonal dependence in the extinction coefficient differences relative to CE Europe. In spring and autumn differences are negative above 5 $-6 \mathrm{~km}$, and positive below, approaching zero at about $2 \mathrm{~km}$. The corresponding differences in AF are positive, with a maximum of $\sim 5 \%$ near the altitude where extinction co- 
efficient differences change from negative to positive (i.e., at $5-6 \mathrm{~km}$ ). In summer, differences in extinction coefficient are again negative above $\sim 6 \mathrm{~km}$ and positive below. Then, differences become again negative below $2 \mathrm{~km}$. Differences in UVB and UVA AF are in this case positive above $4 \mathrm{~km}$, and negative below. Absolute maxima in the positive and negative values are spotted at $5 \mathrm{~km}$ and $2 \mathrm{~km}$ respectively. This is because, when the LIVAS profile is used for the simulations instead of the default, more downwelling photons reach the altitude of $6 \mathrm{~km}$. Then, the excessive interaction between aerosols and photons in the layer between $2 \mathrm{~km}$ and $6 \mathrm{~km}$ leads to decreased AF below about the mid of the layer.

At lower SZAs, differences become very small (Figure A11), while at larger SZAs (Figure A12) differences in the atmosphere increase, especially for UVA. For example, at $80^{\circ}$ differences in the atmosphere reach $20 \%$. At such large SZA relative differences correspond to small absolute differences, and their impact on photochemical processes is less significant.

In the case of the HR profiles (Figure 10), differences follow closely the differences in the extinction coefficient profiles. Maximum absolute differences in HR are $0.5-1 \mathrm{~K} /$ day for SZAs below $60^{\circ}$ and become smaller for larger SZA. Largest differences, of $\sim 1 \mathrm{~K} /$ day were found in winter near the surface for both regions. In summer, using the default profile leads in underestimation of atmospheric heating by SW radiation at $\sim 4 \mathrm{~km}$ over NW Africa by $\sim 0.5 \mathrm{~K} /$ day. It is clear from these results that even for typical aerosol conditions the use of a default profile can lead to significant uncertainties relative to the atmospheric heating or cooling due to the interaction of SW radiation with aerosols.
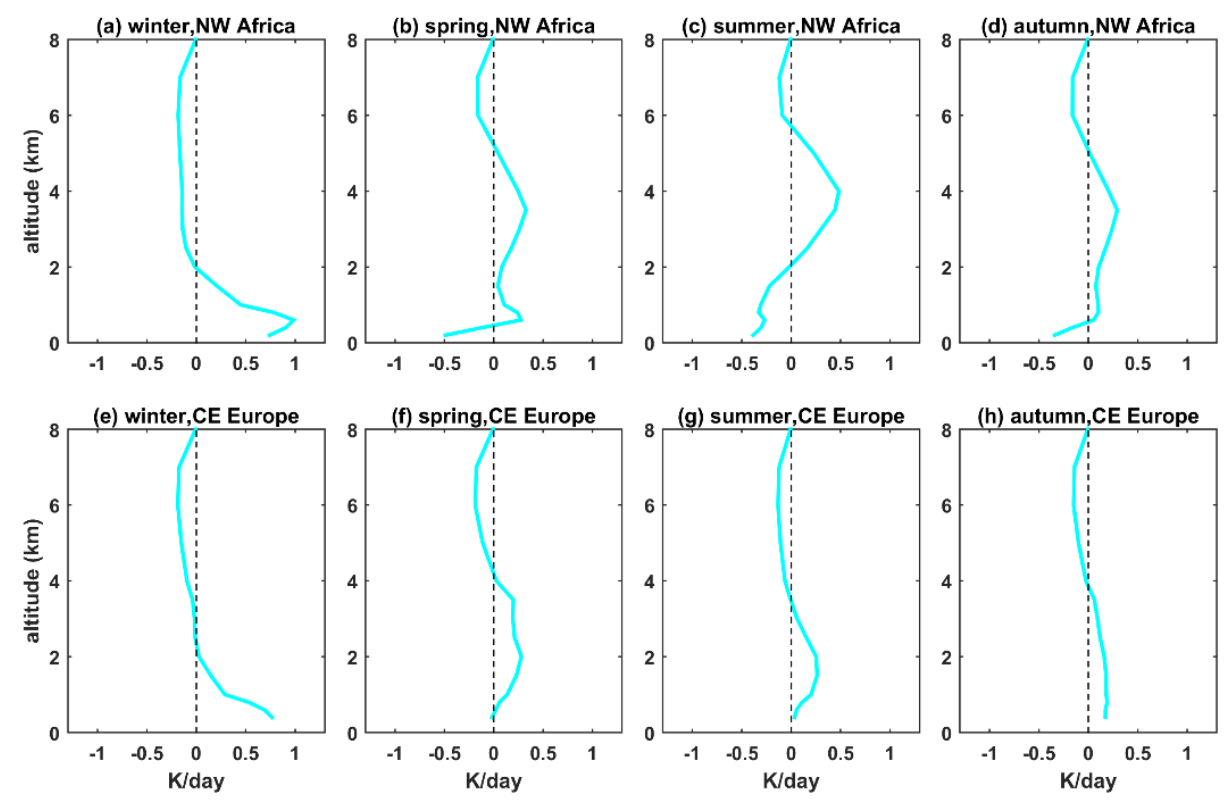

Figure 10. Change (in \%) in the HR (realistic - default) in the first $8 \mathrm{~km}$ of the atmosphere due to the use of the LIVAS profiles instead of the default libRadtran profile. Results are for SZA $=60^{\circ}$. The corresponding graphs for $30^{\circ}$ and $80^{\circ}$ will be provided in the supplement. 

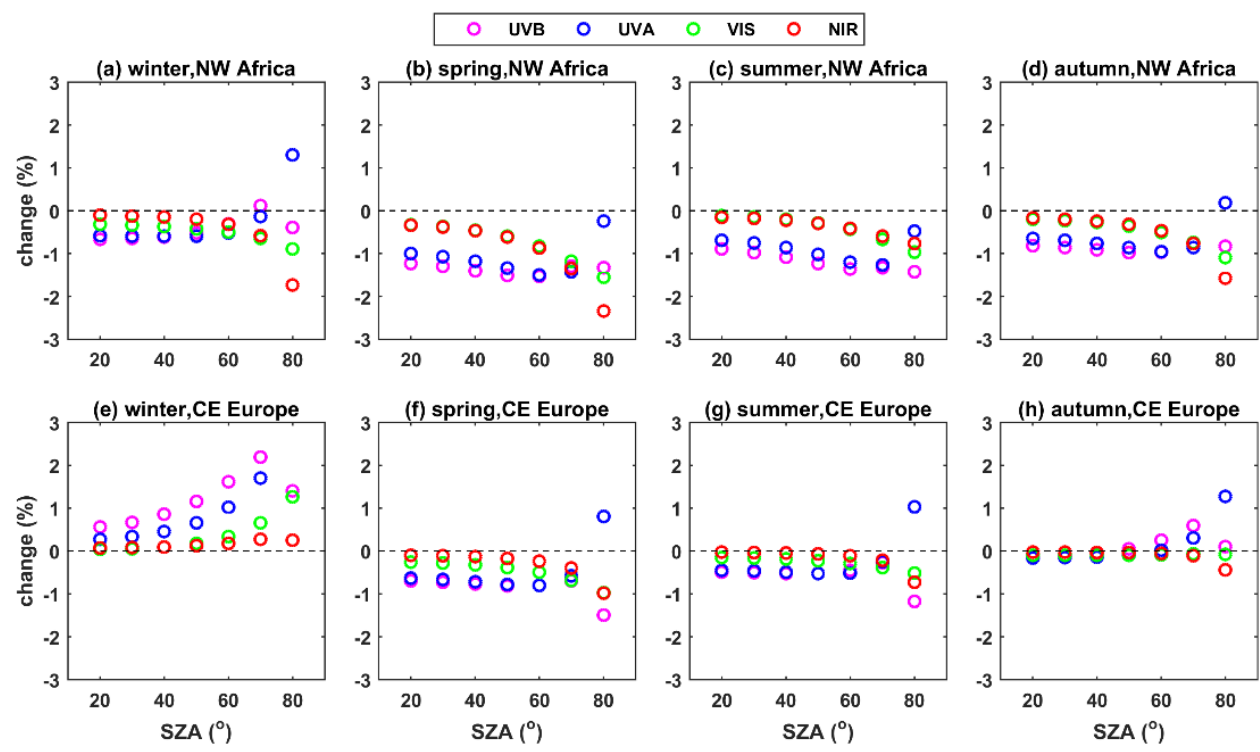

Figure 11. Change (in \%) in the simulated GI reaching the surface due to the use of the LIVAS profiles instead of the default libRadtran profile.

In Figure 11 the differences in the GI at the BOA are presented for each region and each season of the year. In all cases the differences are below 3\%, and especially for VIS and NIR they are in many cases below $0.5 \%$. Given that more than $85 \%$ of total SW irradiance is in the VIS and NIR regions, changes in SW GI are also close to zero. These results confirm that for typical aerosol conditions, using a more realistic profile instead of the default is not necessary for the study of the GI at the Earth surface.
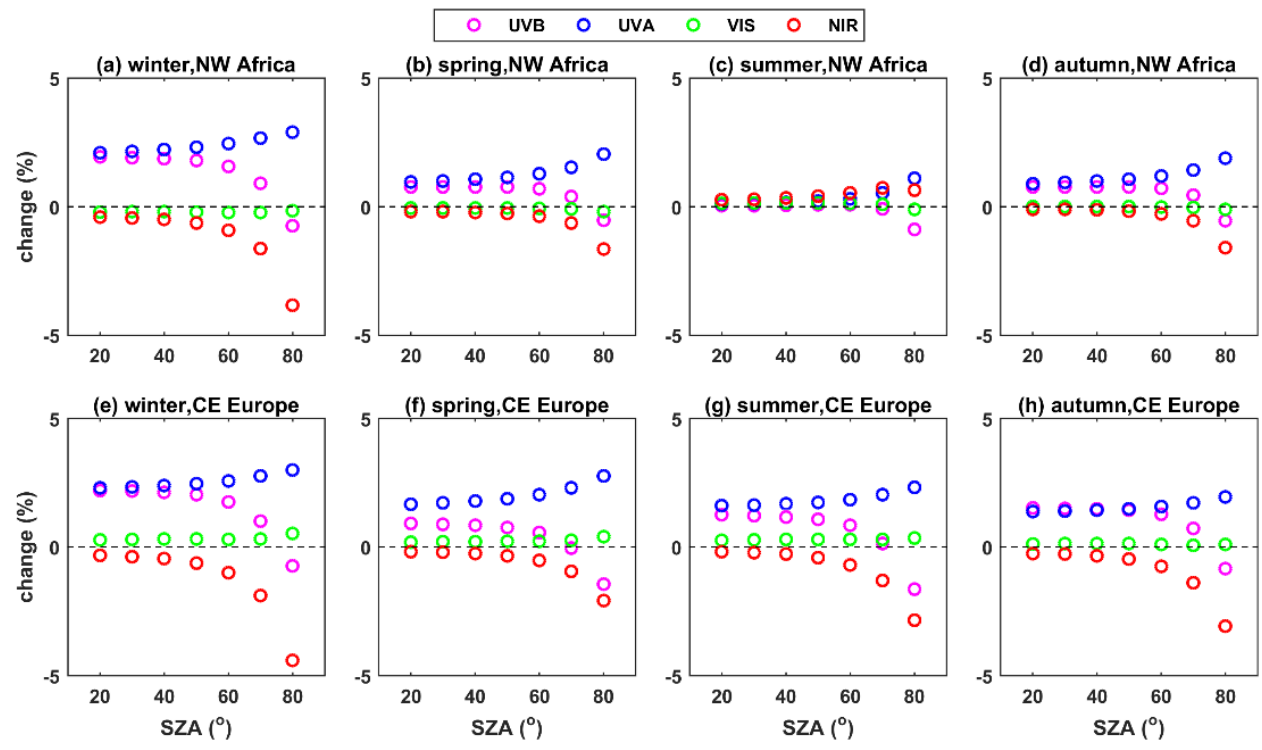

Figure 12. Change (in \%) in the simulated UDI at TOA due to the use of the LIVAS profiles instead of the default libRadtran profile.

Differences in UDI at the TOA are presented in Figure 12. Differences are positive for UVB and UVA, nearly zero for VIS and negative for IR. Given that aerosol extinction is generally overestimated by the default profile at higher and underestimated at lower altitudes in the atmosphere this result was expected based on the analyses performed in Section 3.1. Except for very high SZAs (i.e., $80^{\circ}$ ) differences are smaller than $3 \%$. Changes in SW irradiance (not shown in the graph) are very close to changes in VIS, i.e., between 
0 and $1 \%$. Thus, the results presented in Figure 12 denote nearly zero change of the modeled SW UDI when a more realistic extinction profile is used for typical aerosol conditions with respect to the default profile.

\subsection{Effect of the used extinction profile for strong dust events}

Three Mediterranean sites which are occasionally affected by strong dust episodes have been chosen for the analyses performed in this section. The three sites are presented in Figure 2, and the methodology that has been used for the accomplishment of the RT simulations is described in section 2.5. The differences between the LIVAS (532 nm) extinction coefficient profiles and the default profile for AOD $=1$ are shown in Figure 13. In Figure 14 the corresponding differences in AF are shown for UV (UVB+UVA). Differences in the particular spectral region are presented because of their significance for photochemical processes. In Figure 15 the corresponding differences for HR are shown for the SW irradiance. The results are presented for the three sites for three different SZAs $\left(30^{\circ}, 60^{\circ}\right.$, $\left.80^{\circ}\right)$

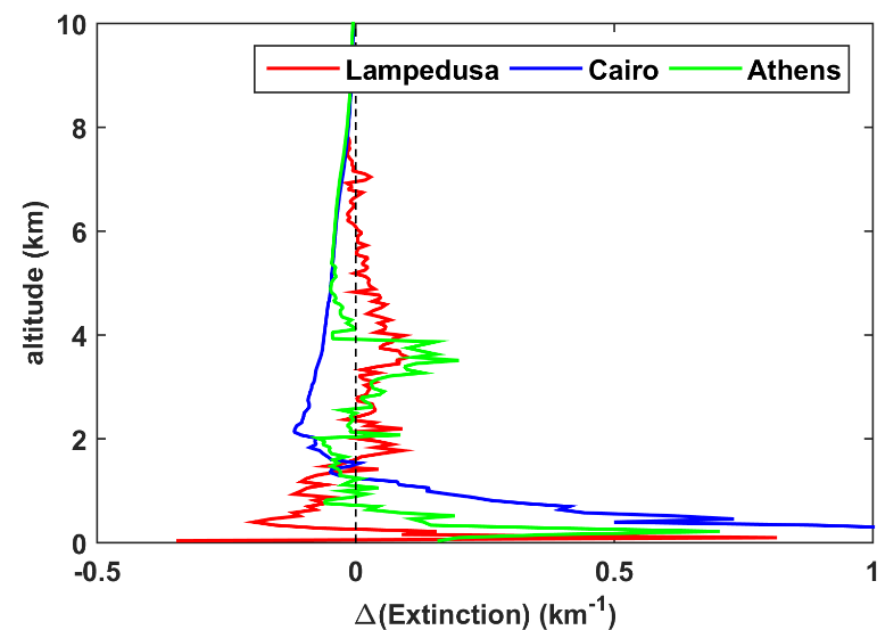

Figure 13. Differences between the $532 \mathrm{~nm}$ LIVAS and the libRadtran default extinction coefficient profiles. The profiles have been scaled to $\mathrm{AOD}=1$ to calculate the differences. The LIVAS profile for each of the three sites is the average of all profiles corresponding to AOD at $532 \mathrm{~nm}$ larger than 0.8 for the period $2006-2018$.
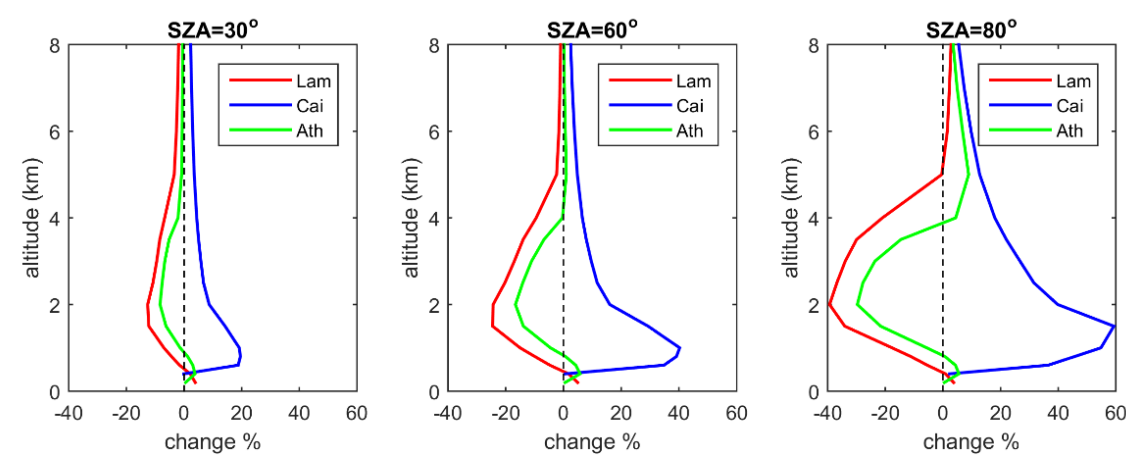

Figure 14. Change (in \%) in AF in the UV in the first $8 \mathrm{~km}$ of the atmosphere due to the use of the LIVAS profiles instead of the default libRadtran profile for $A O D=1$. Results for the three sites and for $\mathrm{SZA}=30^{\circ}, 60^{\circ}$, and $80^{\circ}$ are presented. 

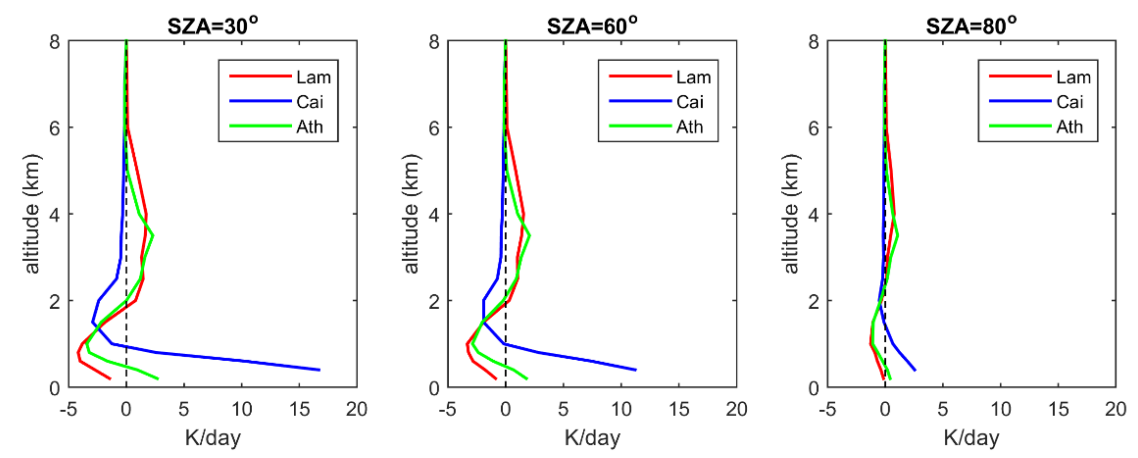

Figure 15. Change (in K/day) in the SW irradiance HR (realistic - default) in the first $8 \mathrm{~km}$ of the atmosphere due to the use of the LIVAS profiles instead of the default libRadtran profile for AOD=1. Results for the three sites and for $\mathrm{SZA}=30^{\circ}, 60^{\circ}$, and $80^{\circ}$ are presented.

The patterns of differences in the extinction coefficient (Figure 13) are quite different for the three sites resulting subsequently to quite different results for the vertical profiles of AF (Figure 14) and HR (Figure 15). Over Cairo, extinction coefficient is overestimated above and underestimated below $\sim 1.5 \mathrm{~km}$ by the default profile. These differences result to increased AF by $20-60 \%$ at the altitude of $\sim 1.5 \mathrm{~km}$ when the LIVAS profile is used. Differences in the extinction coefficient are directly depicted on the HR differences. When the LIVAS profile is used, HR near the surface increases by up to $17 \mathrm{~K} /$ day at $\mathrm{SZA}=20^{\circ}$. Over Athens, the sign of the differences between the LIVAS and the default extinction coefficient profile changes at different altitudes. The overall result is that above $4 \mathrm{~km}$ the differences in $\mathrm{AF}$ are practically zero at $\mathrm{SZAs}$ below $60^{\circ}$. At $\mathrm{SZA}=80^{\circ}$ the $\mathrm{AF}$ is larger when the LIVAS profile is used, by $\sim 10 \%$ at $5 \mathrm{~km}$. From 4 to $1 \mathrm{~km}$ differences are negative, reaching $-10 \%$ to $-30 \%$ at $2 \mathrm{~km}$ depending on SZA. Below $1 \mathrm{~km}$, small positive differences were found, of the order of a few percent. Again, the profile of differences in HR follows the profile of differences in the extinction coefficient, changing between $-3 \mathrm{~K} /$ day and 3 $\mathrm{K} /$ day. In the case of Lampedusa, extinction coefficient is underestimated by the default profile at altitudes between $1.5 \mathrm{~km}$ and $6 \mathrm{~km}$. Below $1.5 \mathrm{~km}$ the difference between LIVAS and the default profile becomes negative, and near the surface it is again positive. Differences in AF are near zero above $5 \mathrm{~km}$ and negative below, reaching $-15 \%$ to $-40 \%$ at about $2 \mathrm{~km}$ depending on SZA. Differences in HR range between $-4 \mathrm{~K} /$ day and $2 \mathrm{~K} /$ day following the pattern of differences in the extinction coefficient.
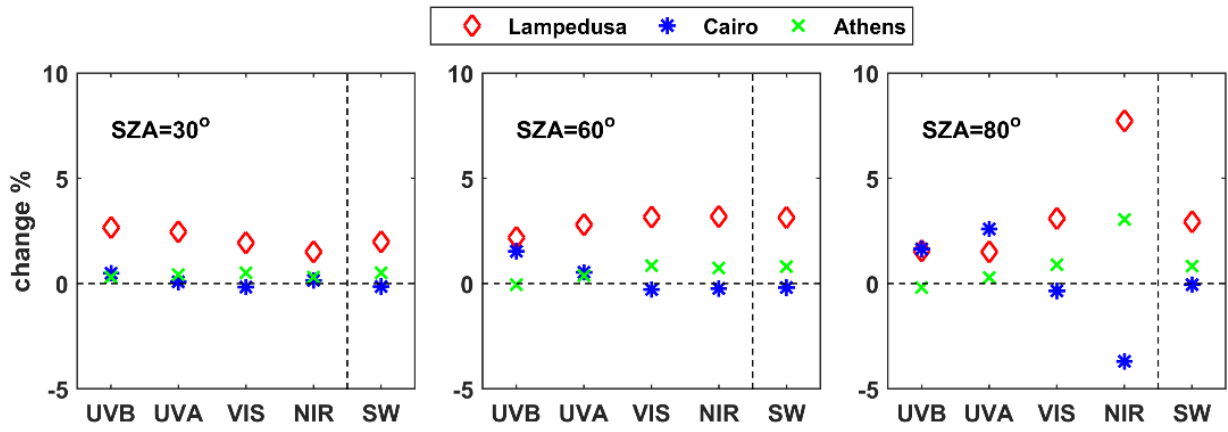

Figure 16. Changes (in \%) in the simulated GI at BOA due to the use of the LIVAS profiles instead of the default profile.

Despite the very high AOD and the significant differences between the LIVAS and the default extinction coefficient profiles, differences in the GI at the BOA are small, for the SW irradiance and for each of the four spectral regions (Figure 16). For SW, differences range from $0 \%$ (over Cairo) to $3 \%$ (over Lampedusa). For SZA $=80^{\circ}$ differences in the NIR region become larger (- $4 \%$ for Cairo and $+8 \%$ for Lampedusa). At the TOA, differences are generally larger relative to the $\mathrm{BOA}$ (between $\pm 10 \%$ ) for individual spectral regions (Figure 17), but they are practically zero for the SW irradiance. 

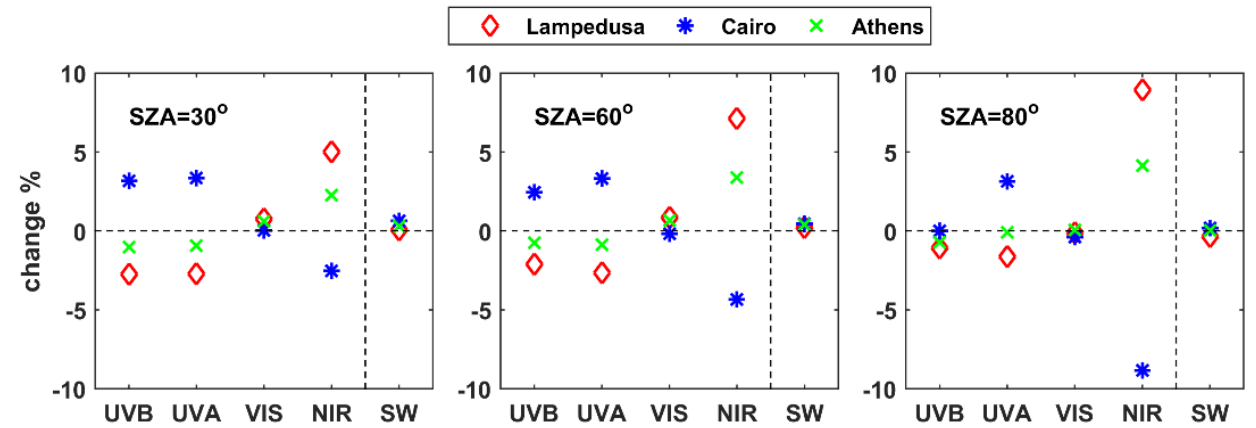

Figure 17. Changes (in \%) in the simulated UDI at TOA due to the use of the LIVAS profiles instead of the default profile.

\section{Summary and conclusions}

In climate modelling studies, as well as in many case studies relative to the radiative effects of aerosols, simplified extinction coefficient profiles are commonly used [21,22]. Very few information is available on how this simplification affects the simulated radiation (e.g., $[20,23])$. In the present study, we exploited the recently developed LIVAS climatology [54] and investigated how changes in the vertical distribution of aerosols affect the distribution of shortwave radiation in the atmosphere under cloudless skies. Analysis was performed for the four spectral bands which constitute the SW radiation: UVB, UVA, VIS, and NIR.

Sensitivity analyses based on artificial aerosol profiles showed that the altitude of the aerosol layer has minor impact on the total shortwave GI at the BOA. Increasing the altitude of the aerosol layer results to slightly more GI at the BOA. Differences increase with increasing SZA, but even at $\mathrm{SZA}=80^{\circ}$ and $\mathrm{AOD}=1$ they are below $10 \%$. Differences can be more significant for individual spectral regions, especially over high albedo surfaces, where increasing the altitude of the layer can lead to increases of the order of $10-15 \%$ in the UVB and UVA regions, even at low SZAs.

For absorbing aerosols $(\mathrm{SSA}=0.75)$ the SW UDI at the TOA does not practically change with changing altitude of the aerosol layer, while for more reflective aerosols (SSA $=0.95$ ) differences are larger, but again exceed $10 \%$ only at $\mathrm{SZA}=80^{\circ}$ and for large height differences in the altitude of the hypothetical layers. These latter differences mainly originate from large differences in the NIR UDI, which increases up to $30 \%$ for SZA $=80^{\circ}$ (when $\mathrm{AOD}=1$ and the altitude of the base of the aerosol layer increases from 0 to $4 \mathrm{~km}$ ). Increasing altitude of the aerosol layer corresponds to negative differences in the UDI in UVB, UVA, and VIS and positive differences for NIR at TOA. At BOA, the signs of differences in NIR are also opposite to the signs of changes in UVB, UVA, and VIS. This is because the changes in the amount of photons that reach the BOA or the TOA are related with different processes in the different spectral regions. As also discussed in Mishra et al. [20] differences in the UV and VIS are mainly related with Rayleigh scattering while differences in the NIR are mainly related with absorption in the atmosphere.

Differences in the radiation profiles are larger in the atmosphere with respect to the TOA and the BOA. Increasing the altitude of the aerosol layer leads to large increase of the SW HR at the level of the layer, and large decrease at the level of L0, with respect to the case of having all aerosols at L0. Differences in AF are negative between the top of the elevated layer and the BOA when the AF profiles for elevated aerosol layers and aerosols at $\mathrm{L} 0$ are compared. For scattering aerosols $(\mathrm{SSA}=0.95)$, differences in AF are more significant for longer (NIR) wavelengths, while for absorbing aerosols (SSA $=0.75$ ), differences are more significant for shorter wavelengths (UVB). Increasing the SZA or the AOD increases the absolute differences, while increasing the surface albedo supresses the differences.

It should be kept in mind that all numbers referred to the above discussion correspond to high AOD and relatively unrealistic distribution of aerosols in the atmosphere. 
However, the use of artificial profiles for the analyses allowed to determine the mechanisms which drive the differences. In order to derive more realistic, and more accurate in a quantitative manner conclusion, the radiation profiles which were derived using LIVAS climatological averages were compared to the radiation profiles derived using the default libRadtran profile, which assumes exponential decrease of the aerosol extinction coefficient with altitude in the troposphere.

As expected, for typical atmospheric and aerosol conditions at CE Europe and NW Africa the differences in the UDI at the TOA and the GI at the BOA when the seasonally averaged LIVAS profiles were used instead of the default profile were, for all spectral bands (and obviously also for the SW radiation), below 5\%. Differences in AF in the atmosphere were in most cases positive (i.e., more AF available for photochemical reactions when the LIVAS profiles were used), up to $10 \%$, with the altitude of the maximum differences ranging between $1 \mathrm{~km}$ and $5 \mathrm{~km}$ depending on the region and the season. This was a consequence of the underestimation of the aerosol extinction by the default profile at low altitudes (near the surface). The only exception was NW Africa in summer, where the default profile overestimated aerosol extinction at lower altitudes. In this case, differences in UV AF at $\sim 2 \mathrm{~km}$ were of the order of $-5 \%$. Given that photochemical reactions at altitudes up to $3 \mathrm{~km}$ may affect the composition and the quality of air inside the boundary layer, differences in AF cannot be considered negligible. Differences in SW HR of the order of 0.5 to $1 \mathrm{~K}$ /day were found at the altitudes of maximum differences between the LIVAS and the default profile. Again, such differences cannot be considered negligible since they can affect atmospheric stability, and subsequently the formation of clouds.

At the three sites considered for the study, using average LIVAS instead of the theoretical extinction coefficient profiles for high AOD resulted to larger differences with respect to the comparison between the radiation profiles for average AOD conditions for the two regions. For Athens, the LIVAS extinction profile is closer to the theoretical, compared to the other two sites, resulting to the smallest differences in the radiation profile among the three sites. Differences in UV AF are negative at the lowest $4 \mathrm{~km}$ for Athens and Lampedusa, reaching $-20 \%$ and $-40 \%$ respectively at $\sim 2 \mathrm{~km}$ when SZA $=80^{\circ}$. At the same SZA differences in Cairo are positive, up to $60 \%$ at $\sim 1.5 \mathrm{~km}$. Such large differences can have a significant impact on atmospheric photochemistry. Differences in SW HR are also very large near the surface reaching $17 \mathrm{~K} /$ day at Cairo for $\mathrm{SZA}=30^{\circ}$. However, even for such high aerosol load, differences at the BOA and the TOA are small, especially for the total SW radiation. Differences in SW UDI at the TOA are nearly zero for all sites, while differences in SW GI are smaller than 3\% at BOA. Differences at individual spectral bands are more significant, mainly for NIR at high SZAs, where they can be of the order of $10 \%$ at TOA and $5-8 \%$ at the BOA.

As already discussed, using a more realistic extinction coefficient profile for the simulations of the vertical profile of the SW radiation leads to small differences at the BOA and the TOA for typical AOD conditions. Thus, using measured profiles for climatological studies of the radiative effects of aerosols is not critical. This is in agreement with the findings of Petrzala et al. for urban aerosols [23]. According to Mishra et al. [20] differences can be more significant for the thermal infrared $(4-20 \mu \mathrm{m})$ spectral region (longwave radiation). The role of aerosol profile can be also more significant in the presence of clouds (e.g., [74]). The present study was however focused on radiative effects in different bands of the SW solar radiation under cloudless-sky conditions.

Even if the results of the present study confirm that accurately determined AOD plays the most significant role in RT simulations of aerosol radiation interactions, aerosol profile retrievals from lidar instruments and satellite observations (e.g., CALIPSO [55] and the upcoming Cloud, Aerosol and Radiation Explorer - EarthCARE mission [75]) could be used to improve such simulations. For individual spectral bands (UV or NIR) using a more realistic profile was found to increase the accuracy in aerosol radiative effect related studies involving elevated aerosol layers and high AOD (e.g., dust or smoke events), even under cloudless-skies, especially over high-albedo terrains. Changes in the vertical distribution of aerosols were found to have a very significant impact in the HR and the AF, 
even for low aerosol loads. Differences in the vertical distribution of AF, especially in the $\mathrm{UV}$, lead to changes in the atmospheric photochemistry and subsequently the atmospheric composition [76,77]. Large differences in HR can affect significantly atmospheric processes such as the formation of clouds [78] or the formation of the PBL [79]. Very large differences in HR and AF were found during dust events over Mediterranean sites, denoting correspondingly large uncertainties in the modelling of atmospheric and photochemical processes if the aerosol vertical distribution is not accurately taken into account. Concluding, the present study intends to be a contribution towards the understanding of the role of vertical distribution of aerosols in the modelling of the transfer of solar radiation in the atmosphere, and to set the basis for further and deeper investigation under more complex conditions, and with respect to other atmospheric processes.

Author Contributions: Conceptualization, S.K.; methodology, I.F., K.P. and S.K.; software, I.F. and K.P.; validation, I.F. and K.P.; formal analysis, I.F., K.P. and E.P.; investigation, I.F. and K.P.; resources, E.P. and V.A.; data curation, I.F., K.P. and E.P.; writing-original draft preparation, I.F.; writing - review and editing, K.P., E.P., V.A., C.K., and S.K.; visualization, I.F. and K.P. supervision, S.K.; project administration, C.K.; funding acquisition, C.K. All authors have read and agreed to the published version of the manuscript.

Funding: This study has been funded by European Commission project EuroGEO e-shape (grant agreement no. 820852).

Data Availability Statement: The LIVAS database and products are available upon request from Vassilis Amiridis (vamoir@noa.gr), Emmanouil Proestakis (proestakis@noa.gr), and/or Eleni Marinou (elmarinou@noa.gr). All other data used in this study are also freely available upon request by the corresponding author.

Acknowledgments: Vassilis Amiridis acknowledges support from the ERC Consolidator Grant 2016 D-TECT: “Does dust TriboElectrification affect our ClimaTe?” (grant no. 725698).

Conflicts of Interest: The authors declare no conflict of interest. 


\section{Appendix A}

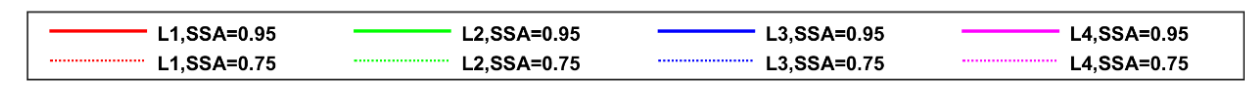
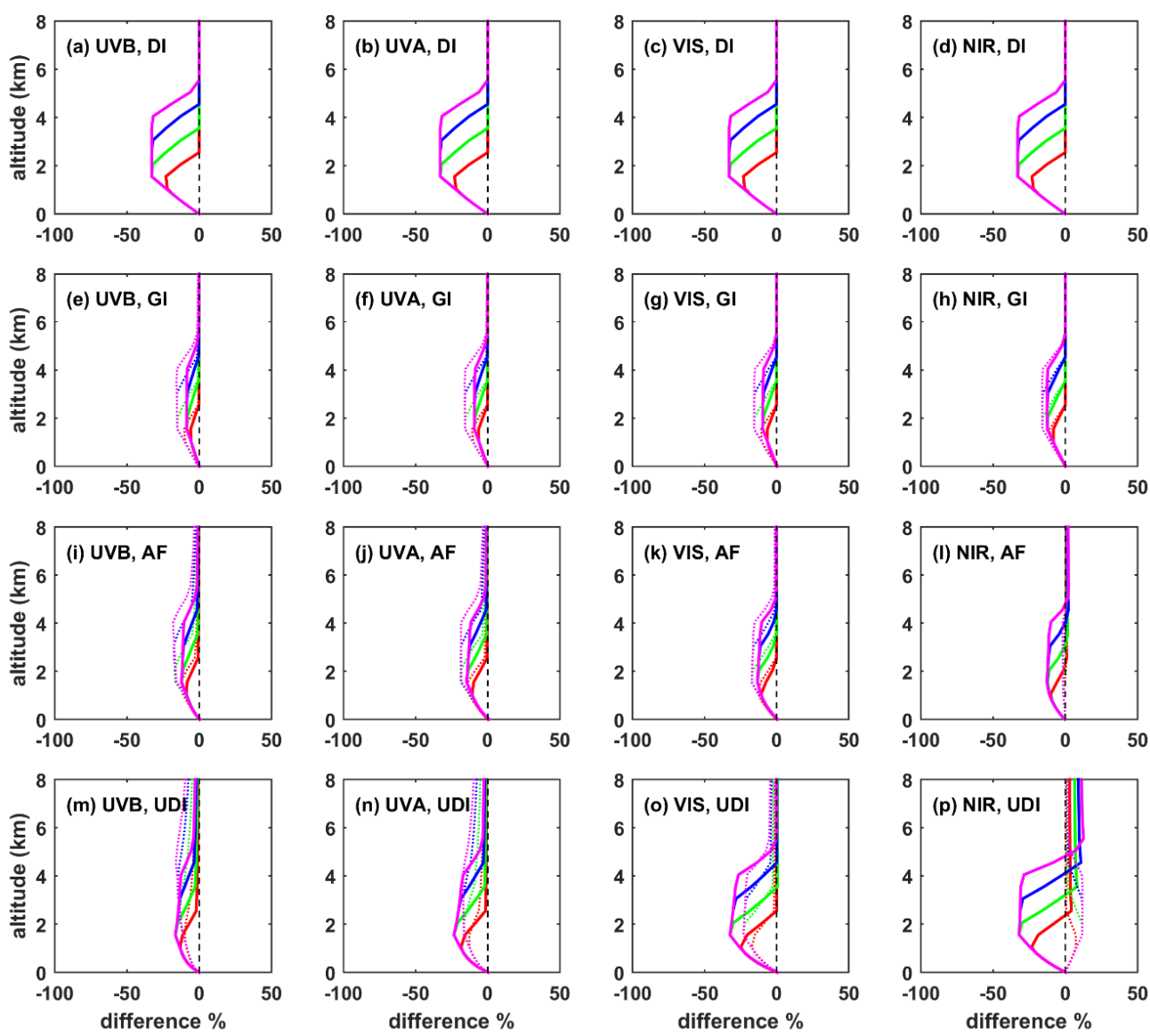

Figure A1. Same as Figure 3, but for AOD=0.2 instead of AOD=1. 


\begin{tabular}{|c|c|c|c|}
\hline $\begin{array}{l}\longrightarrow 1, S S A=0.95 \\
\text { L1,SSA }=0.75\end{array}$ & $\begin{array}{r}\mathrm{L} 2, \mathrm{SSA}=0.95 \\
\mathrm{~L} 2, \mathrm{SSA}=0.75\end{array}$ & $\begin{array}{l}\text { L3,SSA }=0.95 \\
\text { L3,SSA }=0.75\end{array}$ & $\begin{array}{r}\text { L4,SSA }=0.95 \\
\text { L4,SSA }=0.75\end{array}$ \\
\hline
\end{tabular}
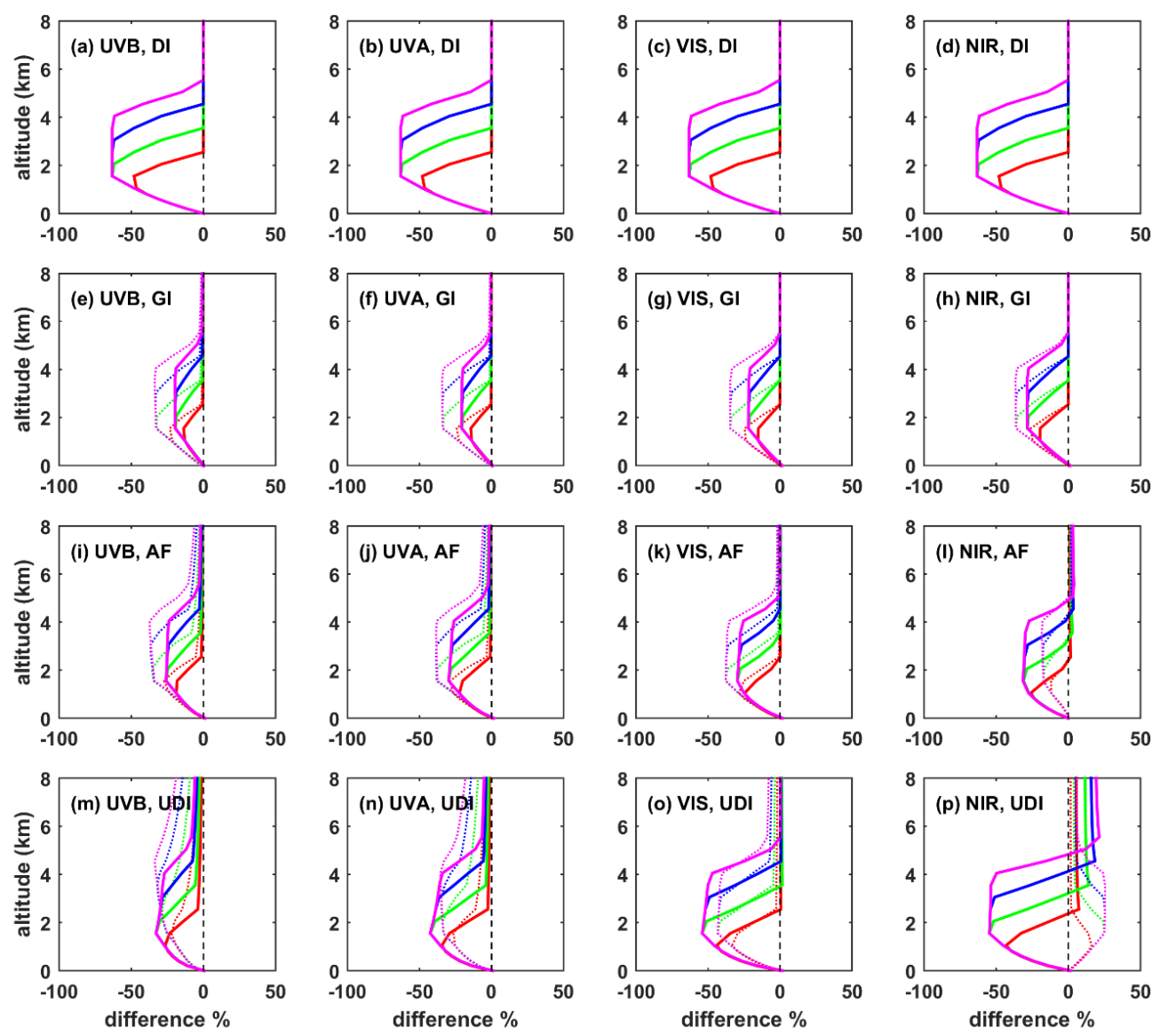

Figure A2. Same as Figure 3, but for AOD=0.5 instead of AOD=1. 


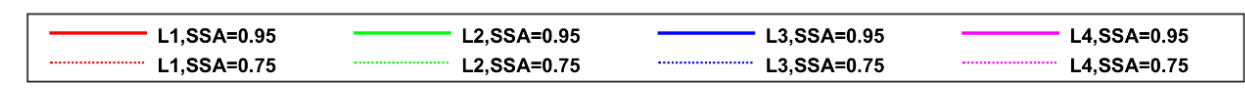
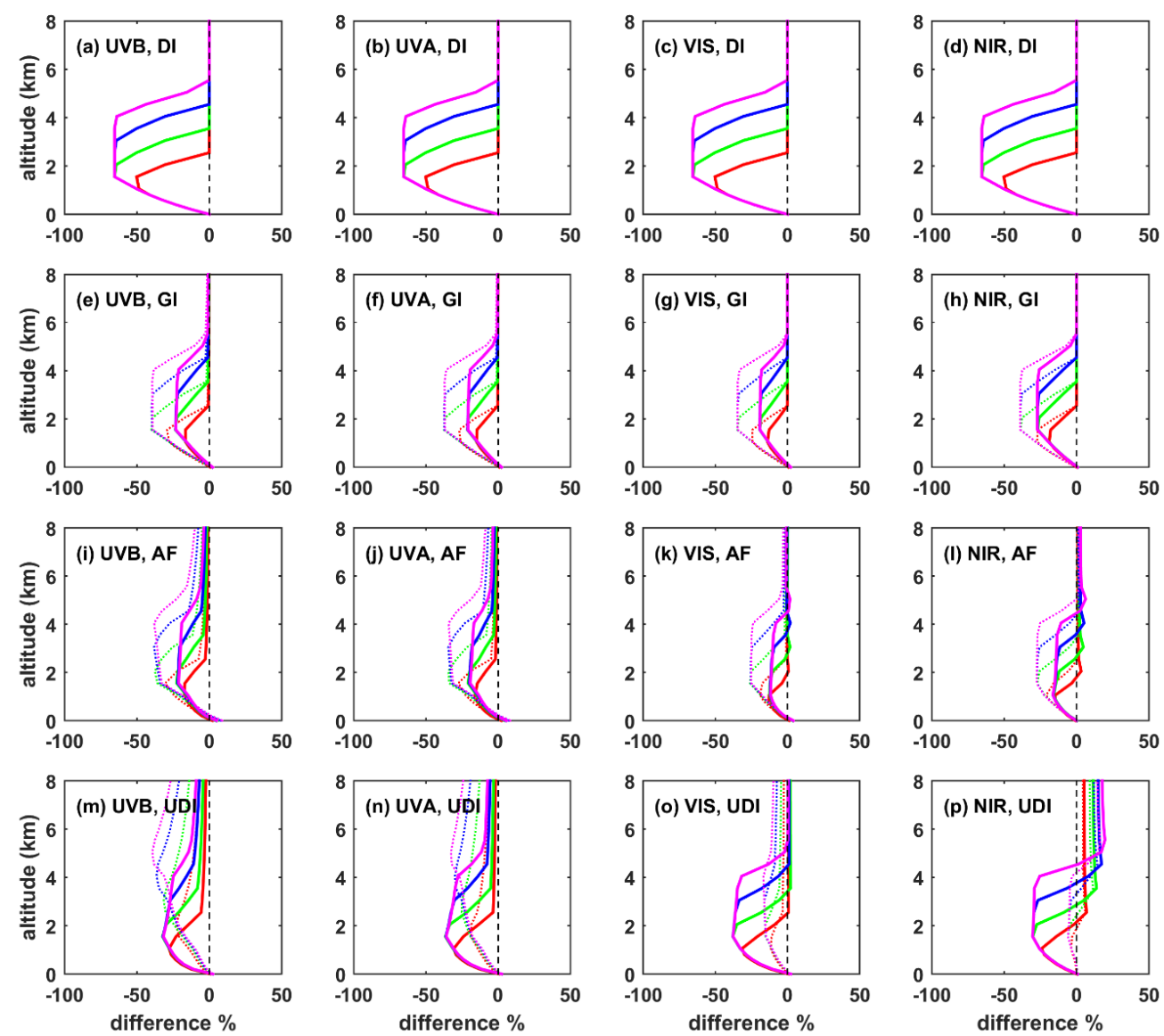

Figure A3. Same as Figure 3, but for $\mathrm{SZA}=20^{\circ}$ instead of $\mathrm{SZA}=60^{\circ}$. 


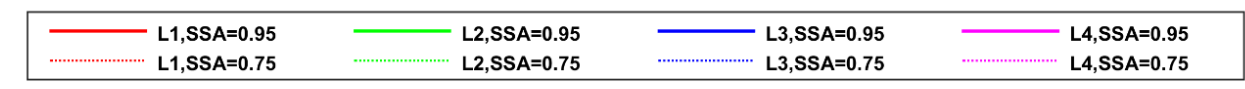
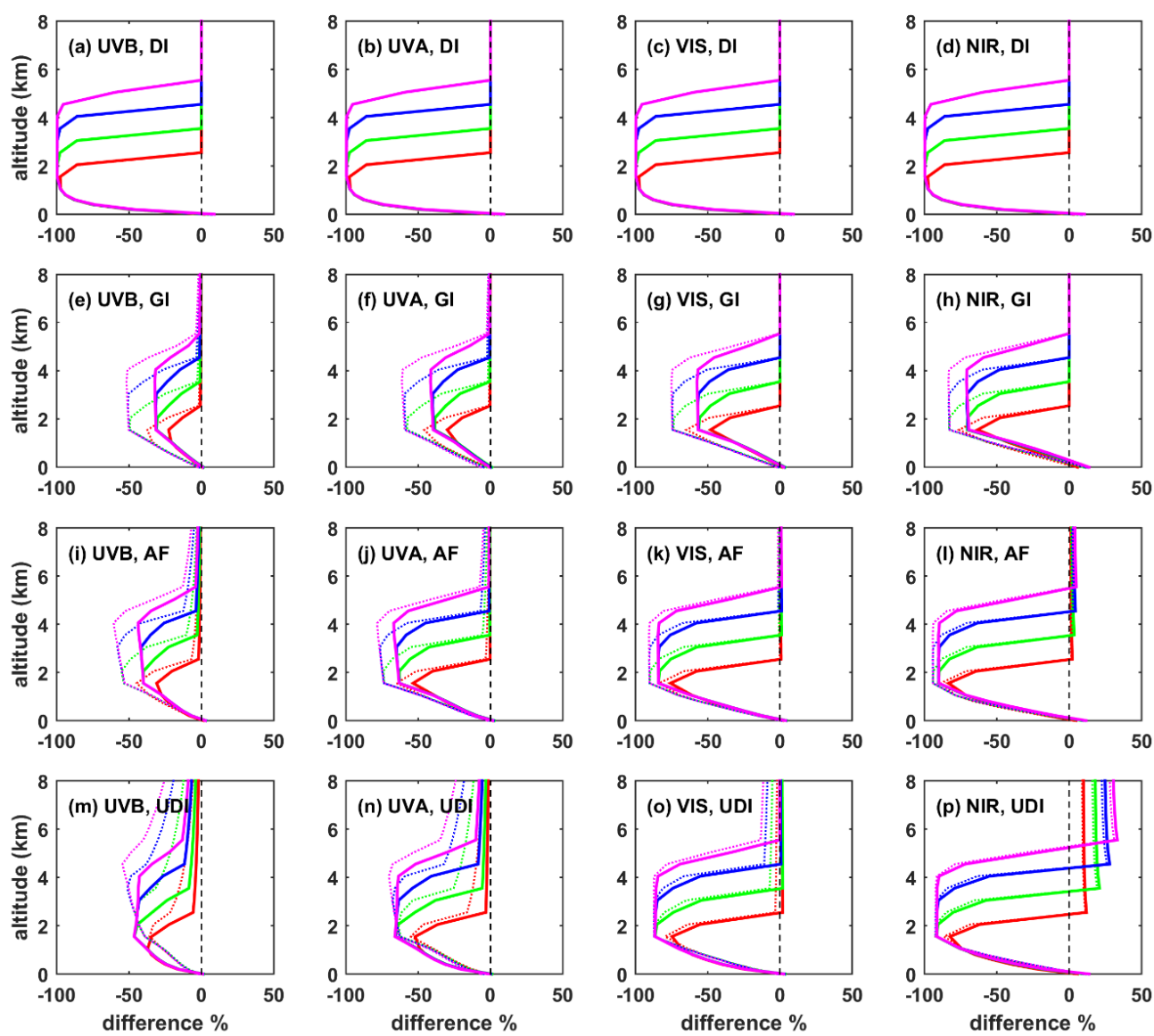

Figure A4. Same as Figure 3, but for $\mathrm{SZA}=80^{\circ}$ instead of $\mathrm{SZA}=60^{\circ}$. 


\begin{tabular}{|c|c|c|c|}
\hline $\mathrm{L} 1, \mathrm{SSA}=0.95$ & $\mathrm{~L} 2, \mathrm{SSA}=0.95$ & $\longrightarrow$ L3,SSA $=0.95$ & $\longrightarrow$ L4,SSA $=0.95$ \\
\hline L1,SSA $=0.75$ & L2,SSA $=0.75$ & L3,SSA $=0.75$ & L4,SSA $=0.75$ \\
\hline
\end{tabular}
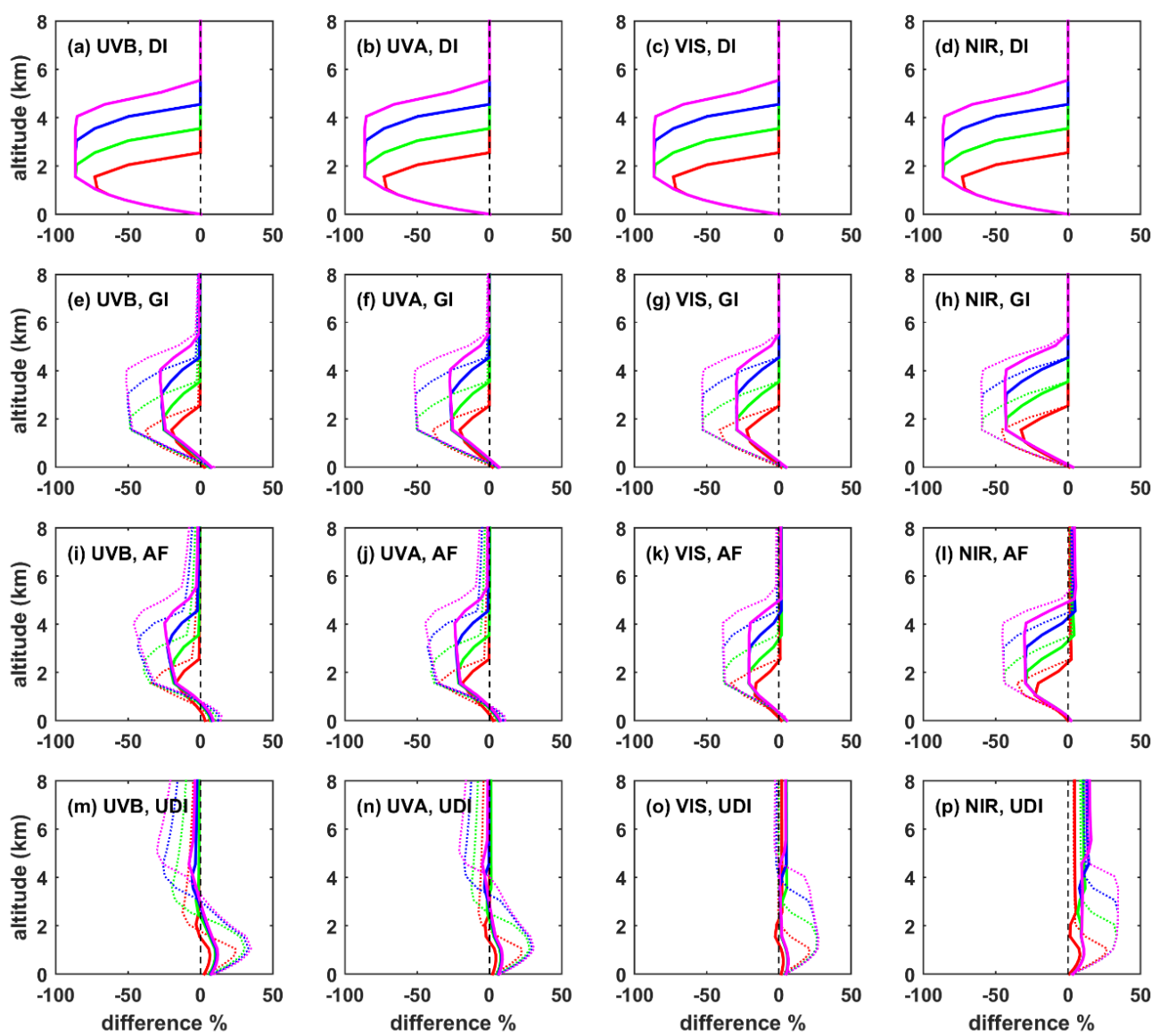

Figure A5. Same as Figure 3, but for surface albedo=0.8 instead of 0.1.
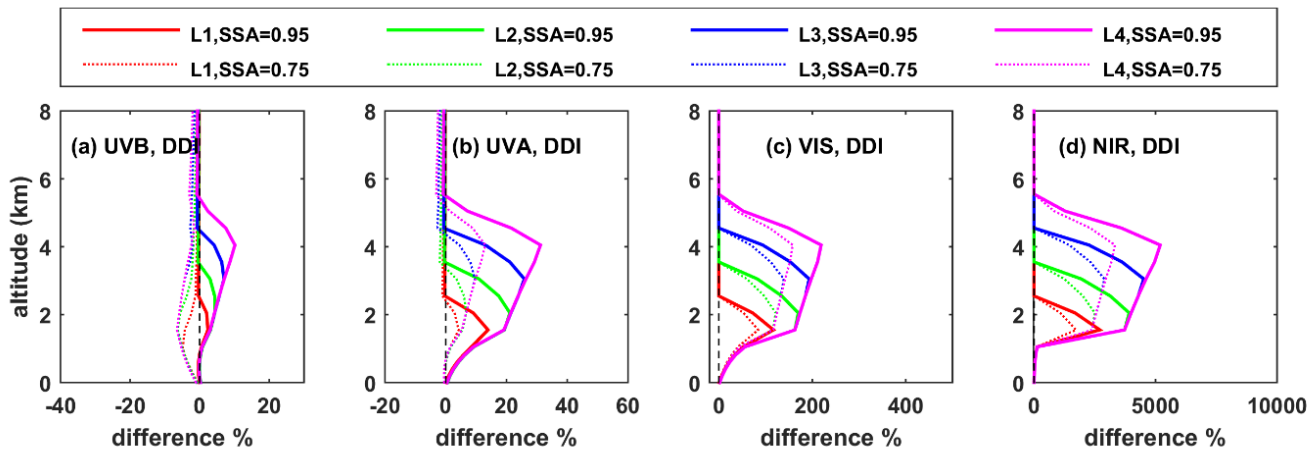

Figure A6. Same as Figure 4, but for AOD=0.2 instead of AOD=1. 

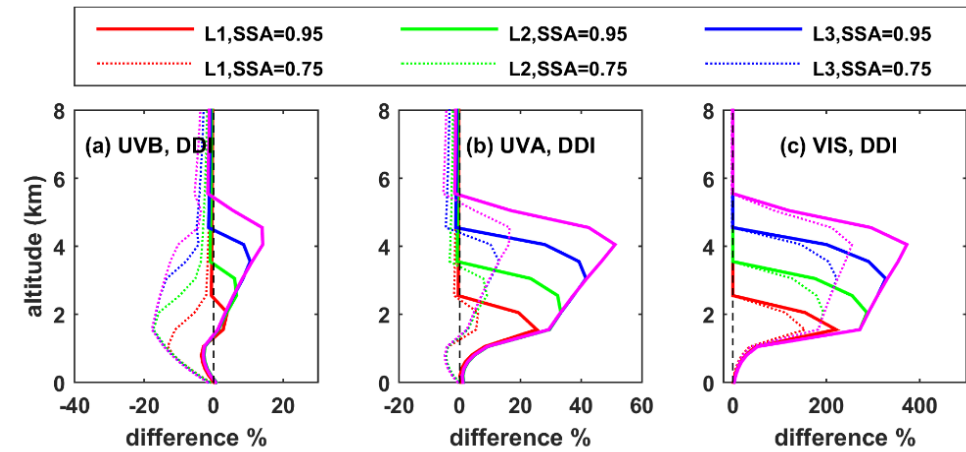

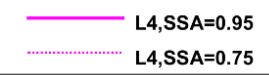

Figure A7. Same as Figure 4, but for AOD=0.5 instead of AOD=1.
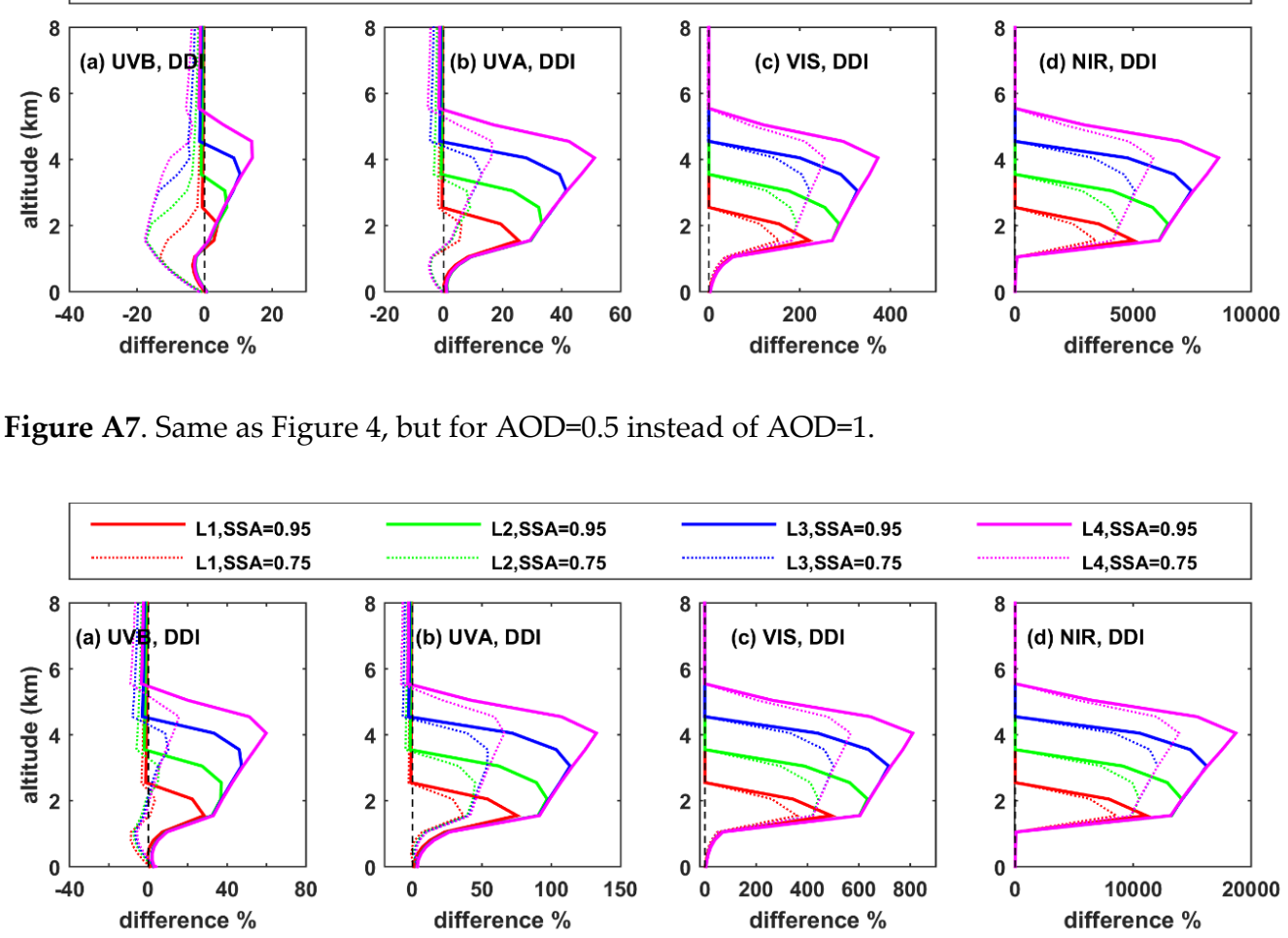

Figure A8. Same as Figure 4, but for $\mathrm{SZA}=20^{\circ}$ instead of $60^{\circ}$. Note that the $\mathrm{x}$-axis scale is different relative to Figure 4.
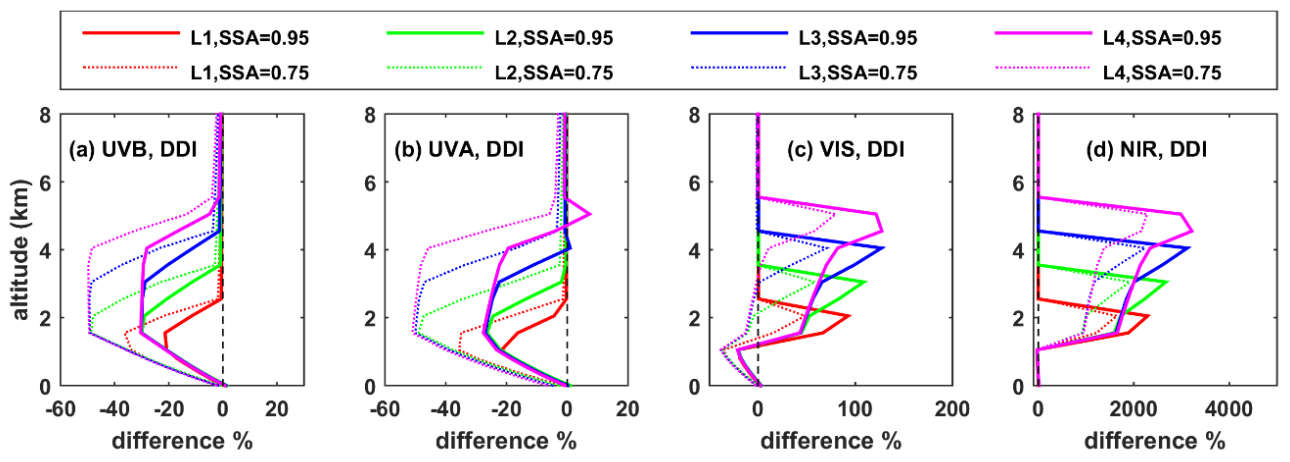

Figure A9. Same as Figure 4, but for $\mathrm{SZA}=80^{\circ}$ instead of $60^{\circ}$. Note that the $\mathrm{x}$-axis scale is different relative to Figure 4. 

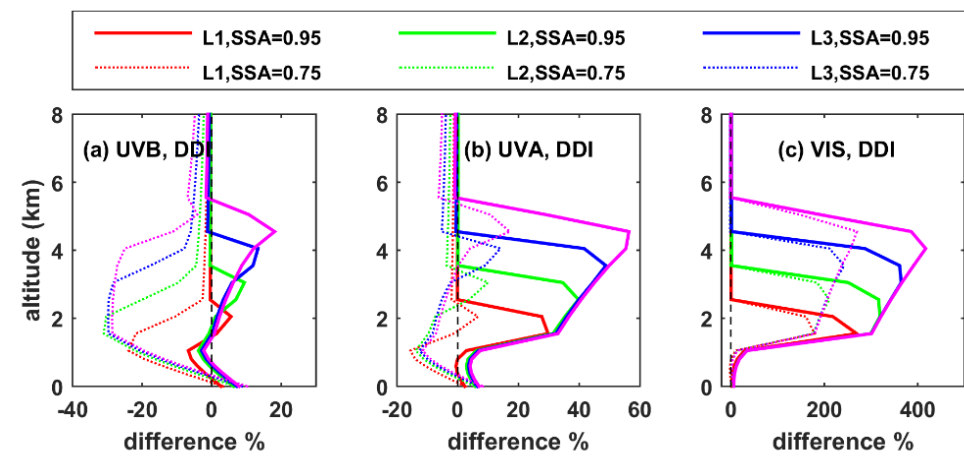

L4,SSA $=0.95$

Figure A10. Same as Figure 4, but for surface albedo=0.8 instead of surface albedo=0.1.
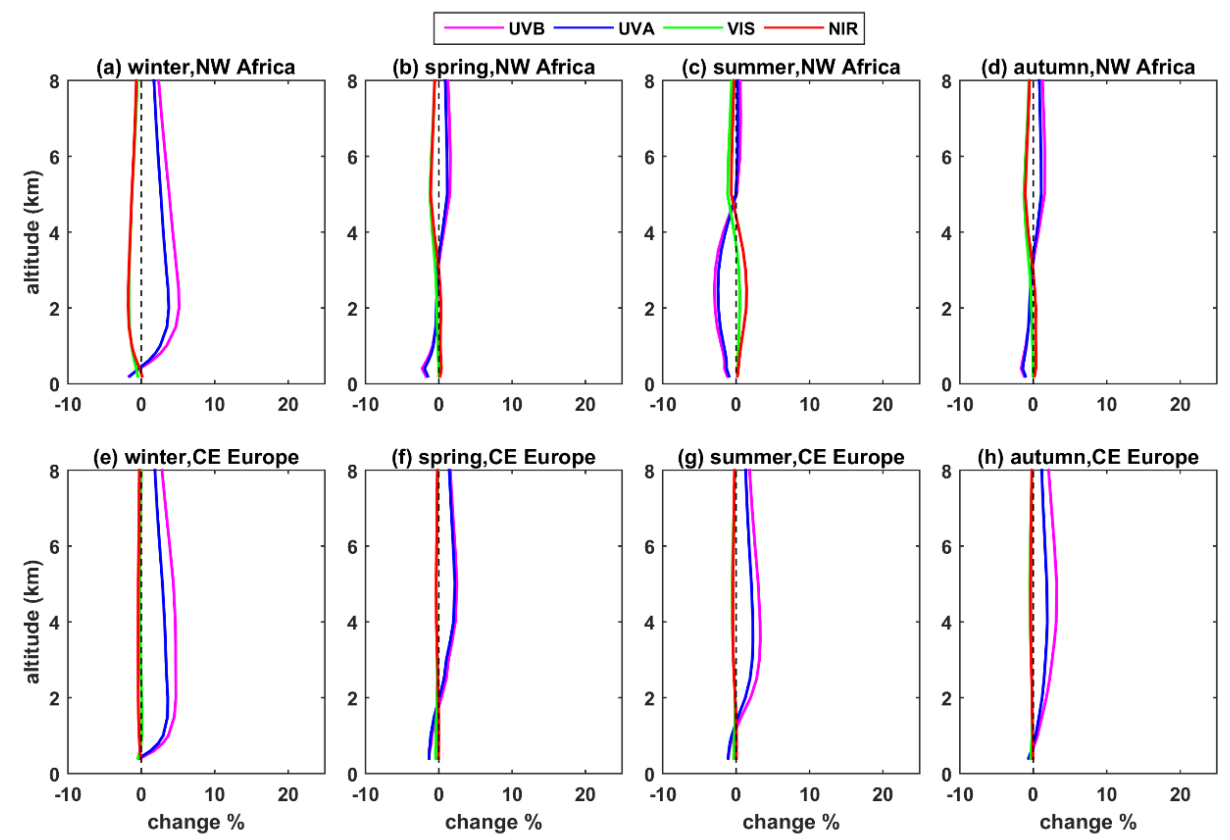

Figure A11. Same as Figure 9, but for $\mathrm{SZA}=30^{\circ}$ instead of $\mathrm{SZA}=60^{\circ}$. 

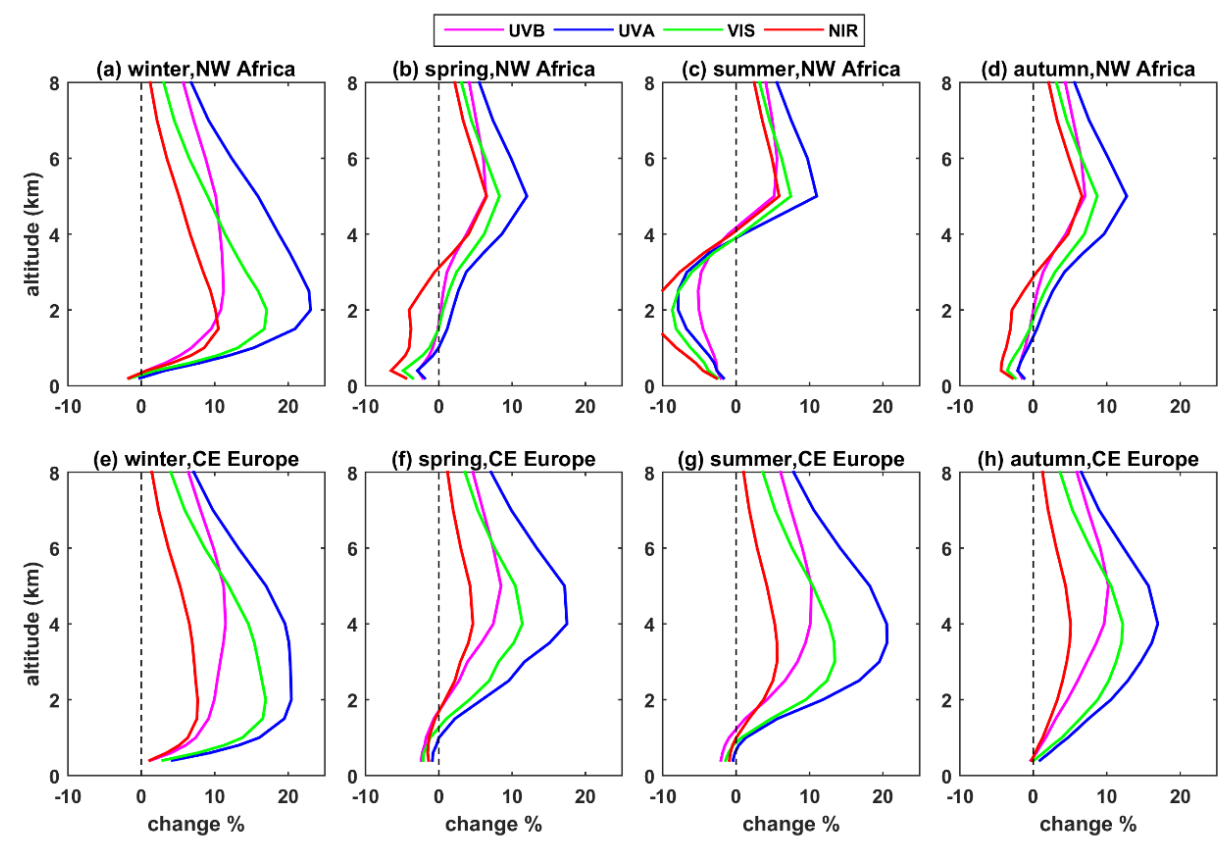

Figure A12. Same as Figure 9, but for $\mathrm{SZA}=80^{\circ}$ instead of $\mathrm{SZA}=60^{\circ}$.
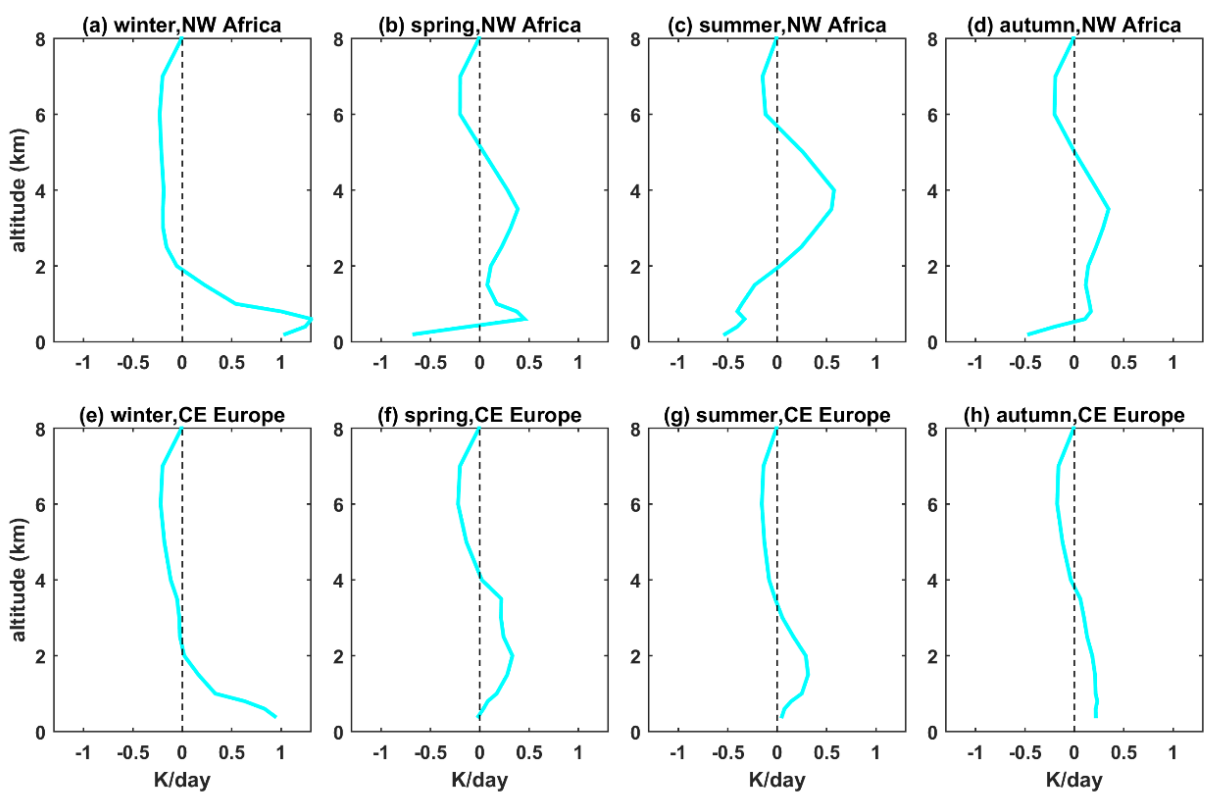

Figure A13. Same as Figure 10, but for $\mathrm{SZA}=30^{\circ}$ instead of $\mathrm{SZA}=60^{\circ}$. 

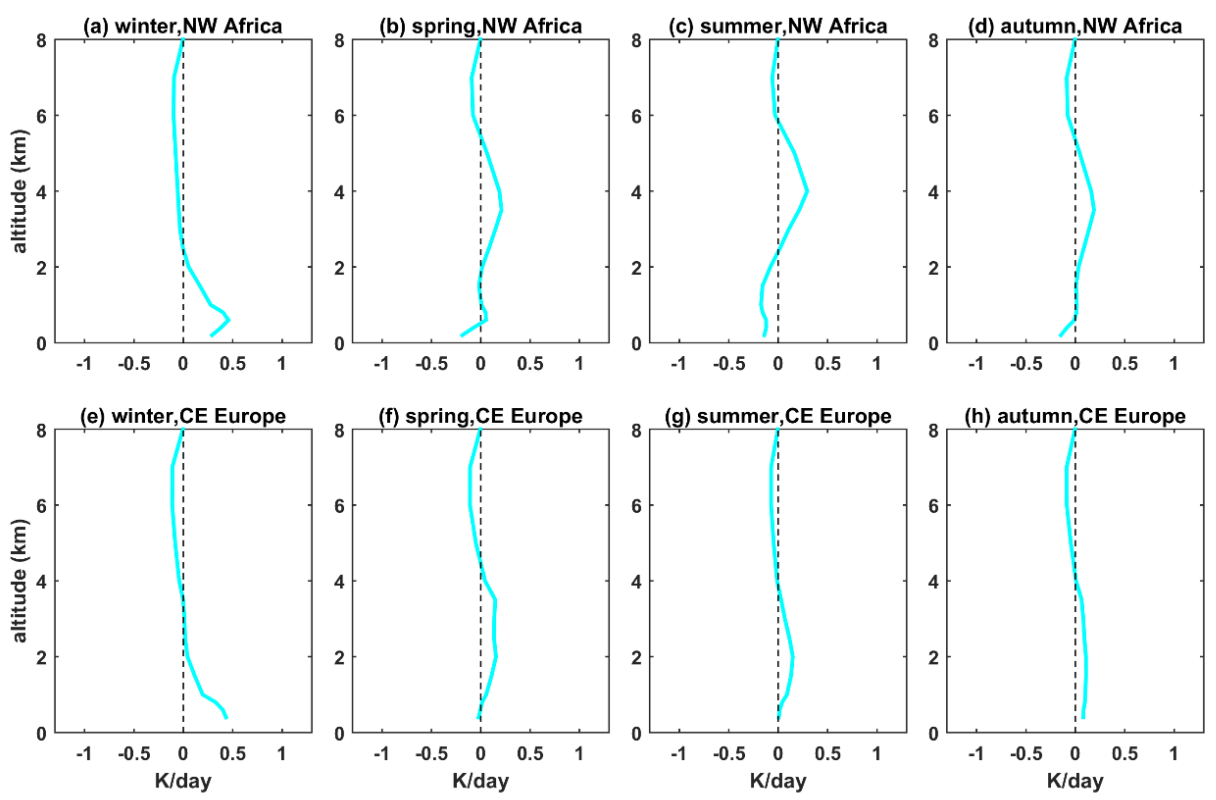

Figure A14. Same as Figure 10, but for $\mathrm{SZA}=80^{\circ}$ instead $60^{\circ}$. 


\section{References}

1. Wild, M. Global dimming and brightening: A review. J. Geophys. Res. Atmos. 2009, 114. https://doi.org/10.1029/2008JD011470.

2. Wild, M. Decadal changes in radiative fluxes at land and ocean surfaces and their relevance for global warming. WIREs Clim. Chang. 2016, 7, 91-107. https://doi.org/10.1002/wcc.372.

3. Wild, M.; Folini, D.; Henschel, F.; Fischer, N.; Müller, B. Projections of long-term changes in solar radiation based on CMIP5 climate models and their influence on energy yields of photovoltaic systems. Sol. Energy 2015, 116, 12-24. https://doi.org/10.1016/j.solener.2015.03.039.

4. IPCC Climate Change 2013: The Physical Science Basis. Contribution of Working Group I to the Fifth Assessment Report of the Intergovernmental Panel on Climate Change [Stocker, T.F., D. Qin, G.-K. Plattner, M. Tignor, S.K. Allen, J. Boschung, A. Nauels, Y. Xia,; 2013;

5. Otto, S.; Bierwirth, E.; Weinzierl, B.; Kandler, K.; Esselborn, M.; Tesche, M.; Schladitz, A.; Wendisch, M.; Trautmann, T. Solar radiative effects of a Saharan dust plume observed during SAMUM assuming spheroidal model particles. Tellus $B$ Chem. Phys. Meteorol. 2009, 61, 270-296. 10.1111/j.1600-0889.2008.00389.x.

6. Otto, S.; de Reus, M.; Trautmann, T.; Thomas, A.; Wendisch, M.; Borrmann, S. Atmospheric radiative effects of an in situ measured Saharan dust plume and the role of large particles. Atmos. Chem. Phys. 2007, 7, 4887-4903. 10.5194/acp-7-4887-2007.

7. Zeng, L.; Zhang, A.; Wang, Y.; Wagner, N.L.; Katich, J.M.; Schwarz, J.P.; Schill, G.P.; Brock, C.; Froyd, K.D.; Murphy, D.M.; et al. Global Measurements of Brown Carbon and Estimated Direct Radiative Effects. Geophys. Res. Lett. 2020, 47, e2020GL088747. https://doi.org/10.1029/2020GL088747.

8. Hess, M.; Koepke, P.; Schult, I. Optical Properties of Aerosols and Clouds: The Software Package OPAC. Bull. Am. Meteorol. Soc. 1998, 79, 831-844. 10.1175/1520-0477(1998)079<0831:OPOAAC>2.0.CO;2.

9. Tsekeri, A.; Lopatin, A.; Amiridis, V.; Marinou, E.; Igloffstein, J.; Siomos, N.; Solomos, S.; Kokkalis, P.; Engelmann, R.; Baars, H.; et al. GARRLiC and LIRIC: strengths and limitations for the characterization of dust and marine particles along with their mixtures. Atmos. Meas. Tech. 2017, 10, 4995-5016. 10.5194/amt-10-4995-2017.

10. Chen, L. Uncertainties in solar radiation assessment in the United States using climate models. Clim. Dyn. 2021, 56, 665-678. 10.1007/s00382-020-05498-7.

11. Boé, J.; Somot, S.; Corre, L.; Nabat, P. Large discrepancies in summer climate change over Europe as projected by global and regional climate models: causes and consequences. Clim. Dyn. 2020, 54, 2981-3002. 10.1007/s00382-020-05153-1.

12. Bartók, B.; Wild, M.; Folini, D.; Lüthi, D.; Kotlarski, S.; Schär, C.; Vautard, R.; Jerez, S.; Imecs, Z. Projected changes in surface solar radiation in CMIP5 global climate models and in EURO-CORDEX regional climate models for Europe. Clim. Dyn. 2017, 49, 2665-2683. 10.1007/s00382-016-3471-2.

13. Lakkala, K.; Kujanpää, J.; Brogniez, C.; Henriot, N.; Arola, A.; Aun, M.; Auriol, F.; Bais, A.F.; Bernhard, G.; De Bock, V.; et al. Validation of the TROPOspheric Monitoring Instrument (TROPOMI) surface UV radiation product. Atmos. Meas. Tech. 2020, 13, 6999-7024. 10.5194/amt-13-6999-2020.

14. Zempila, M.M.; Fountoulakis, I.; Taylor, M.; Kazadzis, S.; Arola, A.; Koukouli, M.E.; Bais, A.; Meleti, C.; Balis, D. Validation of OMI erythemal doses with multi-sensor ground-based measurements in Thessaloniki, Greece. Atmos. Environ. 2018, 183, 106-121. https://doi.org/10.1016/j.atmosenv.2018.04.012.

15. Merrouni, A.A.; Ghennioui, A.; Wolfertstetter, F.; Mezrhab, A. The uncertainty of the HelioClim-3 DNI data under Moroccan climate. AIP Conf. Proc. 2017, 1850, 140002. 10.1063/1.4984510.

16. Witthuhn, J.; Hünerbein, A.; Filipitsch, F.; Wacker, S.; Meilinger, S.; Deneke, H. Aerosol properties and aerosol-radiation interactions in clear-sky conditions over Germany. Atmos. Chem. Phys. 2021, 21, 14591-14630. 10.5194/acp-21-14591-2021.

17. Raptis, I.-P.; Kazadzis, S.; Eleftheratos, K.; Amiridis, V.; Fountoulakis, I. Single Scattering Albedo's Spectral Dependence Effect on UV Irradiance. Atmos. 2018, 9. 10.3390/atmos9090364.

18. Bergstrom, R.W.; Pilewskie, P.; Russell, P.B.; Redemann, J.; Bond, T.C.; Quinn, P.K.; Sierau, B. Spectral absorption properties of atmospheric aerosols. Atmos. Chem. Phys. 2007, 7, 5937-5943. 10.5194/acp-7-5937-2007. 
19. Fountoulakis, I.; Natsis, A.; Siomos, N.; Drosoglou, T.; Bais, A.F. Deriving Aerosol Absorption Properties from Solar Ultraviolet Radiation Spectral Measurements at Thessaloniki, Greece. Remote Sens. 2019, 11. 10.3390/rs11182179.

20. Mishra, A.K.; Koren, I.; Rudich, Y. Effect of aerosol vertical distribution on aerosol-radiation interaction: A theoretical prospect. Heliyon 2015, 1, e00036. https://doi.org/10.1016/j.heliyon.2015.e00036.

21. Stevens, B.; Fiedler, S.; Kinne, S.; Peters, K.; Rast, S.; Müsse, J.; Smith, S.J.; Mauritsen, T. MACv2-SP: a parameterization of anthropogenic aerosol optical properties and an associated Twomey effect for use in CMIP6. Geosci. Model Dev. 2017, 10, 433452. 10.5194/gmd-10-433-2017.

22. Shettle, E. Models of aerosols, clouds, and precipitation for atmospheric propagation studies. AGARD Conf. Proce. $1990,1$.

23. Petrzala, J. Assessment of influence of urban aerosol vertical profile on clear-sky diffuse radiance pattern. J. Sol. Energy Eng. 2021, 1-7. 10.1115/1.4053259.

24. Marinou, E.; Amiridis, V.; Binietoglou, I.; Tsikerdekis, A.; Solomos, S.; Proestakis, E.; Konsta, D.; Papagiannopoulos, N.; Tsekeri, A.; Vlastou, G.; et al. Three-dimensional evolution of Saharan dust transport towards Europe based on a 9-year EARLINET-optimized CALIPSO dataset. Atmos. Chem. Phys. 2017, 17, 5893-5919. 10.5194/acp-17-5893-2017.

25. Langmann, B.; Folch, A.; Hensch, M.; Matthias, V. Volcanic ash over Europe during the eruption of Eyjafjallajökull on Iceland, April-May 2010. Atmos. Environ. 2012, 48, 1-8. https://doi.org/10.1016/j.atmosenv.2011.03.054.

26. Bernard, A.; Rose, W.I. The injection of sulfuric acid aerosols in the stratosphere by the El Chichón volcano and its related hazards to the international air traffic. Nat. Hazards 1990, 3, 59-67. 10.1007/BF00144974.

27. Osborne, M.; Malavelle, F.F.; Adam, M.; Buxmann, J.; Sugier, J.; Marenco, F.; Haywood, J. Saharan dust and biomass burning aerosols during ex-hurricane Ophelia: observations from the new UK lidar and sun-photometer network. Atmos. Chem. Phys. 2019, 19, 3557-3578. 10.5194/acp-19-3557-2019.

28. Vaughan, G.; Wareing, D.; Ricketts, H. Measurement Report: Lidar measurements of stratospheric aerosol following the 2019 Raikoke and Ulawun volcanic eruptions. Atmos. Chem. Phys. 2021, 21, 5597-5604. 10.5194/acp-21-5597-2021.

29. Labonne, M.; Bréon, F.-M.; Chevallier, F. Injection height of biomass burning aerosols as seen from a spaceborne lidar. Geophys. Res. Lett. 2007, 34. https://doi.org/10.1029/2007GL029311.

30. Garratt, J.R. Review: the atmospheric boundary layer. Earth-Science Rev. 1994, 37, 89-134. https://doi.org/10.1016/00128252(94)90026-4.

31. Soupiona, O.; Papayannis, A.; Kokkalis, P.; Foskinis, R.; Sánchez Hernández, G.; Ortiz-Amezcua, P.; Mylonaki, M.; Papanikolaou, C.-A.; Papagiannopoulos, N.; Samaras, S.; et al. EARLINET observations of Saharan dust intrusions over the northern Mediterranean region (2014-2017): properties and impact on radiative forcing. Atmos. Chem. Phys. 2020, 20, 1514715166. 10.5194/acp-20-15147-2020.

32. Herut, B.; Rahav, E.; Tsagaraki, T.M.; Giannakourou, A.; Tsiola, A.; Psarra, S.; Lagaria, A.; Papageorgiou, N.; Mihalopoulos, N.; Theodosi, C.N.; et al. The Potential Impact of Saharan Dust and Polluted Aerosols on Microbial Populations in the East Mediterranean Sea, an Overview of a Mesocosm Experimental Approach . Front. Mar. Sci. 2016, 3, 226.

33. Fountoulakis, I.; Kosmopoulos, P.; Papachristopoulou, K.; Raptis, I.-P.; Mamouri, R.-E.; Nisantzi, A.; Gkikas, A.; Witthuhn, J.; Bley, S.; Moustaka, A.; et al. Effects of Aerosols and Clouds on the Levels of Surface Solar Radiation and Solar Energy in Cyprus. Remote Sens. 2021, 13. 10.3390/rs13122319.

34. Kosmopoulos, P.G.; Kazadzis, S.; El-Askary, H.; Taylor, M.; Gkikas, A.; Proestakis, E.; Kontoes, C.; El-Khayat, M.M. EarthObservation-Based Estimation and Forecasting of Particulate Matter Impact on Solar Energy in Egypt. Remote Sens. $2018,10$. 10.3390/rs10121870.

35. Revell, L.E.; Kuma, P.; Le Ru, E.C.; Somerville, W.R.C.; Gaw, S. Direct radiative effects of airborne microplastics. Nature 2021, 598, 462-467. 10.1038/s41586-021-03864-x.

36. Trainic, M.; Flores, J.M.; Pinkas, I.; Pedrotti, M.L.; Lombard, F.; Bourdin, G.; Gorsky, G.; Boss, E.; Rudich, Y.; Vardi, A.; et al. Airborne microplastic particles detected in the remote marine atmosphere. Commun. Earth Environ. 2020, 1, 64. 10.1038/s43247-020-00061-y. 
37. Allen, S.; Allen, D.; Baladima, F.; Phoenix, V.R.; Thomas, J.L.; Le Roux, G.; Sonke, J.E. Evidence of free tropospheric and longrange transport of microplastic at Pic du Midi Observatory. Nat. Commun. 2021, 12, 7242. 10.1038/s41467-021-27454-7.

38. Fasano, G.; Diémoz, H.; Fountoulakis, I.; Cassardo, C.; Kudo, R.; Siani, A.M.; Ferrero, L. Vertical profile of the clear-sky aerosol direct radiative effect in an Alpine valley, by the synergy of ground-based measurements and radiative transfer simulations. Bull. Atmos. Sci. Technol. 2021, 2, 11. 10.1007/s42865-021-00041-w.

39. Thornton, J.M.; Palazzi, E.; Pepin, N.C.; Cristofanelli, P.; Essery, R.; Kotlarski, S.; Giuliani, G.; Guigoz, Y.; Kulonen, A.; Pritchard, D.; et al. Toward a definition of Essential Mountain Climate Variables. One Earth 2021, 4, 805-827. 10.1016/j.oneear.2021.05.005.

40. Pepin, N.; Bradley, R.S.; Diaz, H.F.; Baraer, M.; Caceres, E.B.; Forsythe, N.; Fowler, H.; Greenwood, G.; Hashmi, M.Z.; Liu, X.D.; et al. Elevation-dependent warming in mountain regions of the world. Nat. Clim. Chang. 2015, 5, 424-430. 10.1038/nclimate2563.

41. Lau, K.M.; Kim, M.K.; Kim, K.M. Asian summer monsoon anomalies induced by aerosol direct forcing: the role of the Tibetan Plateau. Clim. Dyn. 2006, 26, 855-864. 10.1007/s00382-006-0114-z.

42. Surabi, M.; James, H.; Larissa, N.; Yunfeng, L. Climate Effects of Black Carbon Aerosols in China and India. Science (80-. ). 2002, 297, 2250-2253. 10.1126/science.1075159.

43. Lau, K.-M.; Kim, K.-M. Observational relationships between aerosol and Asian monsoon rainfall, and circulation. Geophys. Res. Lett. 2006, 33. https://doi.org/10.1029/2006GL027546.

44. Crutzen, P.J.; Zimmermann, P.H. The changing photochemistry of the troposphere. Tellus B Chem. Phys. Meteorol. 1991, 43, 136-151. 10.3402/tellusb.v43i4.15403.

45. Carroll, M.A.; Ridley, B.A.; Montzka, D.D.; Hubler, G.; Walega, J.G.; Norton, R.B.; Huebert, B.J.; Grahek, F.E. Measurements of nitric oxide and nitrogen dioxide during the Mauna Loa Observatory Photochemistry Experiment. J. Geophys. Res. Atmos. 1992, 97, 10361-10374. https://doi.org/10.1029/91JD02296.

46. Topaloglou, C.; Kazadzis, S.; Bais, A.F.; Blumthaler, M.; Schallhart, B.; Balis, D. NO2 and HCHO photolysis frequencies from irradiance measurements in Thessaloniki, Greece. Atmos. Chem. Phys. 2005, 5, 1645-1653. 10.5194/acp-5-1645-2005.

47. Zhang, Y.; Xue, L.; Dong, C.; Wang, T.; Mellouki, A.; Zhang, Q.; Wang, W. Gaseous carbonyls in China's atmosphere: Tempospatial distributions, sources, photochemical formation, and impact on air quality. Atmos. Environ. 2019, $214,116863$. https://doi.org/10.1016/j.atmosenv.2019.116863.

48. Edinger, J.G. Vertical distribution of photochemical smog in Los Angeles basin. Environ. Sci. Technol. 1973, 7, $247-252$. 10.1021/es60075a004.

49. Velasco, E.; Márquez, C.; Bueno, E.; Bernabé, R.M.; Sánchez, A.; Fentanes, O.; Wöhrnschimmel, H.; Cárdenas, B.; Kamilla, A.; Wakamatsu, S.; et al. Vertical distribution of ozone and VOCs in the low boundary layer of Mexico City. Atmos. Chem. Phys. 2008, 8, 3061-3079. 10.5194/acp-8-3061-2008.

50. Diémoz, H.; Barnaba, F.; Magri, T.; Pession, G.; Dionisi, D.; Pittavino, S.; Tombolato, I.K.F.; Campanelli, M.; Della Ceca, L.S.; Hervo, M.; et al. Transport of Po Valley aerosol pollution to the northwestern Alps - Part 1: Phenomenology. Atmos. Chem. Phys. 2019, 19, 3065-3095. 10.5194/acp-19-3065-2019.

51. Liao, H.; Yung, Y.L.; Seinfeld, J.H. Effects of aerosols on tropospheric photolysis rates in clear and cloudy atmospheres. J. Geophys. Res. Atmos. 1999, 104, 23697-23707. https://doi.org/10.1029/1999JD900409.

52. Wang, W.; Li, X.; Shao, M.; Hu, M.; Zeng, L.; Wu, Y.; Tan, T. The impact of aerosols on photolysis frequencies and ozone production in Beijing during the 4-year period 2012-2015. Atmos. Chem. Phys. 2019, 19, 9413-9429. 10.5194/acp-19-9413-2019.

53. Kylling, A.; Webb, A.R.; Kift, R.; Gobbi, G.P.; Ammannato, L.; Barnaba, F.; Bais, A.; Kazadzis, S.; Wendisch, M.; Jäkel, E.; et al. Spectral actinic flux in the lower troposphere: measurement and 1-D simulations for cloudless, broken cloud and overcast situations. Atmos. Chem. Phys. 2005, 5, 1975-1997. 10.5194/acp-5-1975-2005.

54. Amiridis, V.; Marinou, E.; Tsekeri, A.; Wandinger, U.; Schwarz, A.; Giannakaki, E.; Mamouri, R.; Kokkalis, P.; Binietoglou, I.; Solomos, S.; et al. LIVAS: a 3-D multi-wavelength aerosol/cloud database based on CALIPSO and EARLINET. Atmos. Chem. 
Phys. 2015, 15, 7127-7153. 10.5194/acp-15-7127-2015.

55. Winker, D.M.; Pelon, J.; Coakley, J.A.; Ackerman, S.A.; Charlson, R.J.; Colarco, P.R.; Flamant, P.; Fu, Q.; Hoff, R.M.; Kittaka, C.; et al. The CALIPSO Mission: A Global 3D View of Aerosols and Clouds. Bull. Am. Meteorol. Soc. 2010, 91, 1211-1230. 10.1175/2010BAMS3009.1.

56. Gkikas, A.; Proestakis, E.; Amiridis, V.; Kazadzis, S.; Di Tomaso, E.; Tsekeri, A.; Marinou, E.; Hatzianastassiou, N.; Pérez García-Pando, C. ModIs Dust AeroSol (MIDAS): a global fine-resolution dust optical depth data set. Atmos. Meas. Tech. 2021, 14, 309-334. 10.5194/amt-14-309-2021.

57. Proestakis, E.; Amiridis, V.; Marinou, E.; Georgoulias, A.K.; Solomos, S.; Kazadzis, S.; Chimot, J.; Che, H.; Alexandri, G.; Binietoglou, I.; et al. Nine-year spatial and temporal evolution of desert dust aerosols over South and East Asia as revealed by CALIOP. Atmos. Chem. Phys. 2018, 18, 1337-1362. 10.5194/acp-18-1337-2018.

58. Kim, M.-H.; Omar, A.H.; Tackett, J.L.; Vaughan, M.A.; Winker, D.M.; Trepte, C.R.; Hu, Y.; Liu, Z.; Poole, L.R.; Pitts, M.C.; et al. The CALIPSO version 4 automated aerosol classification and lidar ratio selection algorithm. Atmos. Meas. Tech. 2018, 11, 6107-6135. 10.5194/amt-11-6107-2018.

59. Emde, C.; Buras-Schnell, R.; Kylling, A.; Mayer, B.; Gasteiger, J.; Hamann, U.; Kylling, J.; Richter, B.; Pause, C.; Dowling, T.; et al. The libRadtran software package for radiative transfer calculations (version 2.0.1). Geosci. Model Dev. 2016, 9, 1647-1672. 10.5194/gmd-9-1647-2016.

60. Anderson, G.; Clough, S.; Kneizys, F.; Chetwynd, J.; Shettle, E. AFGL Atmospheric Constituent Profiles (0.120km). 1986, 46. 61. Kurucz, R.L. Synthetic Infrared Spectra. Symp. - Int. Astron. Union 1994, 154, 523-531. DOI: 10.1017/S0074180900124805.

62. Buras, R.; Dowling, T.; Emde, C. New secondary-scattering correction in DISORT with increased efficiency for forward scattering. J. Quant. Spectrosc. Radiat. Transf. 2011, 112, 2028-2034. https://doi.org/10.1016/j.jqsrt.2011.03.019.

63. Wandji Nyamsi, W.; Arola, A.; Blanc, P.; Lindfors, A. V; Cesnulyte, V.; Pitkänen, M.R.A.; Wald, L. Technical Note: A novel parameterization of the transmissivity due to ozone absorption in the $k$-distribution method and correlated- $k$ approximation of Kato et al. (1999) over the UV band. Atmos. Chem. Phys. 2015, 15, 7449-7456. 10.5194/acp-15-7449-2015.

64. Kato, S.; Ackerman, T.P.; Mather, J.H.; Clothiaux, E.E. The k-distribution method and correlated-k approximation for a shortwave radiative transfer model. J. Quant. Spectrosc. Radiat. Transf. 1999, 62, 109-121. https://doi.org/10.1016/S00224073(98)00075-2.

65. Mayer, B.; Kylling, A. Technical note: The libRadtran software package for radiative transfer calculations - description and examples of use. Atmos. Chem. Phys. 2005, 5, 1855-1877. 10.5194/acp-5-1855-2005.

66. Inness, A.; Ades, M.; Agustí-Panareda, A.; Barré, J.; Benedictow, A.; Blechschmidt, A.-M.; Dominguez, J.J.; Engelen, R.; Eskes, H.; Flemming, J.; et al. The CAMS reanalysis of atmospheric composition. Atmos. Chem. Phys. 2019, 19, 3515-3556. 10.5194/acp19-3515-2019.

67. Bhartia, P.K. OMI/Aura TOMS-Like Ozone, Aerosol Index, Cloud Radiance Fraction L3 1 day 1 degree x 1 degree V3 (OMTO3d). NASA Goddard Sp. Flight Center, Goddard Earth Sci. Data Inf. Serv. Cent. (GES DISC), Accessed 13 January 20222012. 10.5067/Aura/OMI/DATA3001.

68. Wei, J.; Li, Z.; Peng, Y.; Sun, L. MODIS Collection 6.1 aerosol optical depth products over land and ocean: validation and comparison. Atmos. Environ. 2019, 201, 428-440. https://doi.org/10.1016/j.atmosenv.2018.12.004.

69. Global Modeling and Assimilation Office (GMAO) MERRA-2 tavgM_2d_rad_Nx: 2d,Monthly mean,Time-Averaged,SingleLevel,Assimilation,Radiation Diagnostics V5.12.4, Greenbelt, MD, USA, Goddard Earth Sciences Data and Information Services Center (GES DISC), Accessed: [Data Access Date: 21/12/2021], 10.5067/O.

70. Varotsos, C.A.; Melnikova, I.N.; Cracknell, A.P.; Tzanis, C.; Vasilyev, A. V New spectral functions of the near-ground albedo derived from aircraft diffraction spectrometer observations. Atmos. Chem. Phys. 2014, 14, 6953-6965. 10.5194/acp-14-6953-2014.

71. Feister, U.; Grewe, R. SPECTRAL ALBEDO MEASUREMENTS IN THE UV and VISIBLE REGION OVER DIFFERENT TYPES OF SURFACES. Photochem. Photobiol. 1995, 62, 736-744. https://doi.org/10.1111/j.1751-1097.1995.tb08723.x. 
73. Tanré, D.; Haywood, J.; Pelon, J.; Léon, J.F.; Chatenet, B.; Formenti, P.; Francis, P.; Goloub, P.; Highwood, E.J.; Myhre, G. Measurement and modeling of the Saharan dust radiative impact: Overview of the Saharan Dust Experiment (SHADE). J. Geophys. Res. Atmos. 2003, 108. https://doi.org/10.1029/2002JD003273.

74. Choi, J.-O.; Chung, C.E. Sensitivity of aerosol direct radiative forcing to aerosol vertical profile. Tellus B Chem. Phys. Meteorol. 2014, 66, 24376. 10.3402/tellusb.v66.24376.

75. Illingworth, A.J.; Barker, H.W.; Beljaars, A.; Ceccaldi, M.; Chepfer, H.; Clerbaux, N.; Cole, J.; Delanoë, J.; Domenech, C.; Donovan, D.P.; et al. The EarthCARE Satellite: The Next Step Forward in Global Measurements of Clouds, Aerosols, Precipitation, and Radiation. Bull. Am. Meteorol. Soc. 2015, 96, 1311-1332. 10.1175/BAMS-D-12-00227.1.

76. Brasseur, A.-L.; Ramaroson, R.; Delannoy, A.; Skamarock, W.; Barth, M. Three-Dimensional Calculation of Photolysis Frequencies in the Presence of Clouds and Impact on Photochemistry. J. Atmos. Chem. 2002, 41, $211-237$. 10.1023/A:1014952630482.

77. R., D.R.; S., K.; G., S.; L., C.K.; G., D.B.; N., H.B. The Impact of Aerosols on Solar Ultraviolet Radiation and Photochemical Smog. Science (80-. ). 1997, 278, 827-830. 10.1126/science.278.5339.827.

78. Ding, K.; Huang, X.; Ding, A.; Wang, M.; Su, H.; Kerminen, V.-M.; Petäjä, T.; Tan, Z.; Wang, Z.; Zhou, D.; et al. Aerosolboundary-layer-monsoon interactions amplify semi-direct effect of biomass smoke on low cloud formation in Southeast Asia. Nat. Commun. 2021, 12, 6416. 10.1038/s41467-021-26728-4.

79. Barbaro, E.; Vilà-Guerau de Arellano, J.; Krol, M.C.; Holtslag, A.A.M. Impacts of Aerosol Shortwave Radiation Absorption on the Dynamics of an Idealized Convective Atmospheric Boundary Layer. Boundary-Layer Meteorol. 2013, 148, 31-49. 10.1007/s10546-013-9800-7. 